\title{
Analyzing the Discourses of Science Statistics in the Public Sphere: A Qualitative Study of Quantitative Data
}

by

\author{
Erin Quevillon
}

A thesis submitted to the Faculty of Graduate and Postdoctoral Affairs in partial fulfillment of the requirements for the degree of

Master of Arts

in

Applied Linguistics and Discourse Studies

Carleton University

Ottawa, Ontario

(C) 2021, Erin Quevillon 


\begin{abstract}
The transmission of scientific data from its academic origins to the public sphere has become increasingly complicated with the accessibility of information through online platforms and the rise of social and political issues connected to scientific research findings. Ample research has been done to explore online discourses surrounding science research, but there is an opportunity to explore the use of statistical data in the public sphere on Twitter to better understand the function of science statistics and whether or not they assist in conveying accurate information. Gathering statistics from three seminal scientific research articles relating to health science, vaccines, and climate change, the current study seeks to explore how the statistics are represented on twitter by public actors, and to compare those representations between the separate issues that are connected to each set of statistics. Employing a Foucauldian discourse analysis, the study aims to investigate the following: the effectiveness of statistics as they are used in different spheres of knowledge; any differences in the use of statistics in the three associated arguments; and any connections between the discussion of implications in the original research articles and how the statistics are interpreted by public actors. The analysis demonstrates that statistics do function as an effective rhetorical device, however their presentation must be informed by social contexts in order for them to have their intended influence.
\end{abstract}




\section{Acknowledgements}

I would like to extend my gratitude to everyone who has been involved with this thesis. I am extremely grateful to have experienced the invaluable teachings and guidance that I have received from the SLaLS faculty throughout my last several years at Carleton. All the great educators I have had the opportunity to learn from have played an integral role in my development as a student, and constantly inspire me to go about life with the aim of making a positive impact wherever I can.

I would like to acknowledge and express my appreciation for my committee members. Thank you for taking the time to engage with my work, and for your willingness to contribute your thoughts and expertise. I am grateful to be part of such a supportive academic community.

I am incredibly lucky to have a family who supports me with fervor. Mom, Dad, and Zachary: thank you for helping me through several challenging years and for making my progress possible with your unwavering support.

Finally, I wish to thank Dr. Graham Smart. I was floating through my undergrad until I took my first course with Graham, where I found myself totally inspired by his wealth of knowledge and thoughtful teaching. Years later, I can say with confidence that his presence in my academic journey is what helped me to find my path as a writer and researcher, and my passion for discourse studies. He has been an incredibly helpful and patient supervisor throughout this process. I feel extremely lucky to have had his support and expertise. 


\section{Table of Contents}

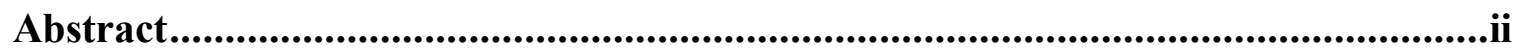

Acknowledgements..........................................................................................................ii

Table of Contents .................................................................................................................iv

List of Appendices..................................................................................................................vi

Chapter 1: Introduction...................................................................................................

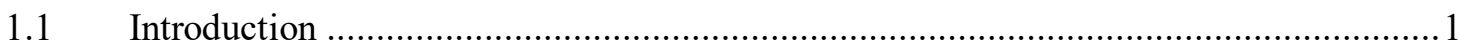

$1.2 \quad$ Background ................................................................................................

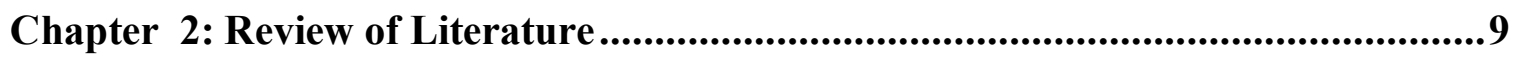

2.1 The Production and Reproduction of Scientific Knowledge .....................................

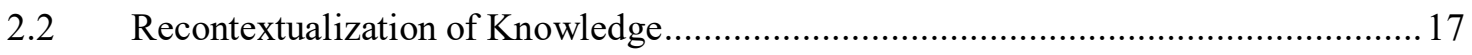

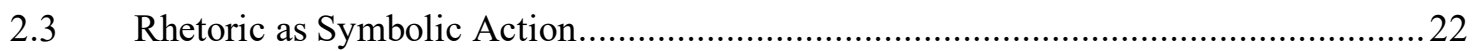

2.4 Political Ideology and (Social) Media Discourse ..................................................2

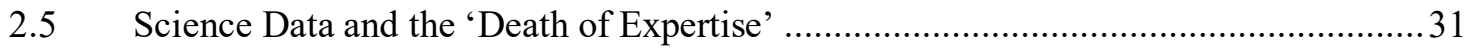

Chapter 3: Theoretical Framework ..............................................................................37

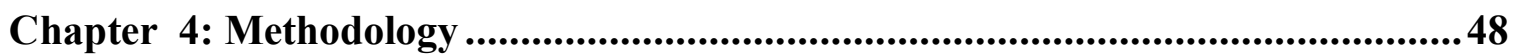

Chapter 5: Analysis ........................................................................................................56

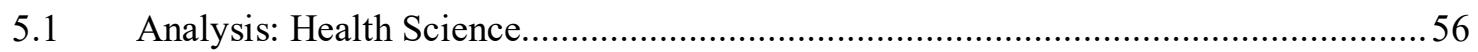

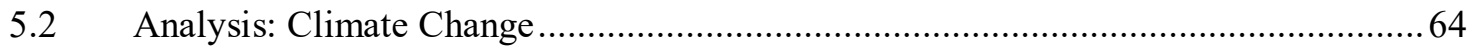

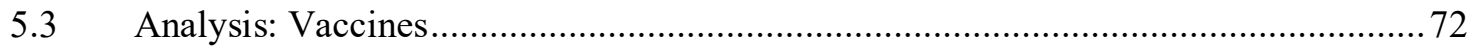

Chapter 6: Discussion of Analysis .............................................................................

Chapter 7: Future Directions and Conclusion .........................................................91

Appendices ......................................................................................................................... 94

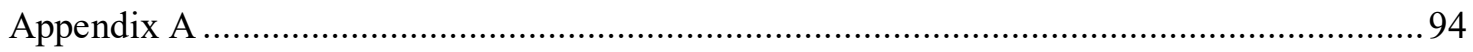


A.1 Harvard Public Health Presentation of Findings.................................................. 104

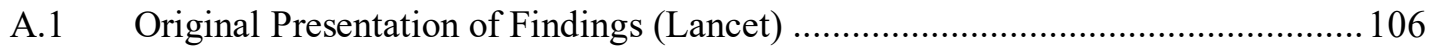

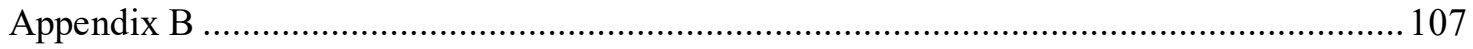

B.1 United Nations Environmental Programme Presentation of Findings ................... 116

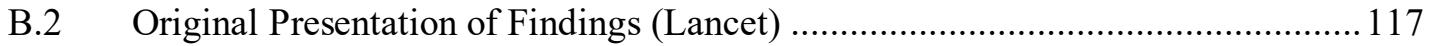

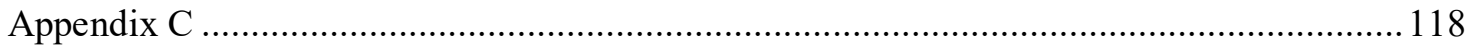

C.1 Oxford Vaccine Group Presentation of Findings.............................................. 124

C.2 Original Presentation of Findings (Lancet) ...................................................... 125

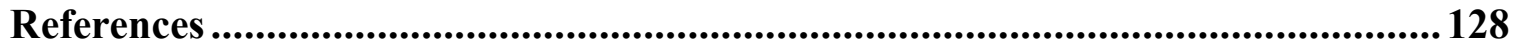




\section{List of Appendices}

Appendix A Error! Bookmark not defined.

A.1 Harvard Public Health Presentation of Findings.......Error! Bookmark not defined.

A.1 Original Presentation of Findings (Lancet) ..............Error! Bookmark not defined. Appendix B Error! Bookmark not defined.

B.1 United Nations Environmental Programme Presentation of Findings .............. Error! Bookmark not defined.

B.2 Original Presentation of Findings (Lancet) ..............Error! Bookmark not defined. Appendix C Error! Bookmark not defined.

C.1 Oxford Vaccine Group Presentation of Findings......Error! Bookmark not defined.

C.2 Original Presentation of Findings (Lancet) ..............Error! Bookmark not defined. 


\section{Chapter 1: Introduction}

\subsection{Introduction}

Research shaping the discussion surrounding the transmission of information between different spheres of knowledge throughout the recent history of discourse studies has evolved and developed to produce several accepted understandings of the process. Knowledge from the science fields in particular has provided a complex area of investigation for how it is transmitted and reproduced in spheres external to its academic origins. Statistics derived from scientific research have maintained their credibility through the longstanding process of stringent research standards fundamental to the disciplines from which they derive, but it is becoming increasingly evident that the authority of knowledge they carry is decreasing in the public sphere. The ongoing conversation at the basis of this discursive process is what has allowed for advancements in how we may understand reproduced numerical data, and through that has cast light on some of the issues with and consequences of science data losing its public influence. Published research on the topic (Hajer, 2005; Smart, 2011) points to the multifaceted nature of the discourses surrounding information from the science fields and the resulting public debates they often prompt; however, there is room for further investigation specifically into scientific statistics for the opportunity to examine the impact of numbers on public debate, or perhaps that of public debate on numbers.

Taking a Foucauldian approach to analyzing the online discourses that include public interpretations of knowledge from three science fields - health sciences, environmental sciences, and biology - the purpose of the current study is to explore how statistics from science research can be effectively transmitted into the public sphere to 
mitigate the spread of misinformation online. With the evolution of social media platforms there have been significant changes in the past few decades in terms of how and where the discussions are had, as well as who is involved with those discussions. Meanwhile, there has also been an increased level of controversy around the implications of scientific data for how it affects human behaviour and for how it is impacted by social and political contexts; with these two overarching themes at hand, it is a worthwhile investigation to examine this developing scenario through the lens of discourse analysis.

Accordingly, the questions the current discussion attempts to answer are: (1) does the presentation of statistics in public debates online operate as an effective rhetorical device?; (2) what are the evident ideologies that oppose the statistical findings in each debate and how do they affect the discourses?; (3) what are the differences in how the statistics are presented and accepted between the explored debates?; and (4) are there any connections between the original presentation of the statistics in academic journals and how they are taken up in the public sphere?

The current study is contextualized with a review of relevant literature backgrounding the focal topic: beginning with an overview of the various areas of research in discourse studies that have shaped the discourses in question, including the construction of scientific knowledge, recontextualization and rhetoric, and the sociopolitical context of new media discourse, essential knowledge to an informed analysis is provided. Continuing with background literature, the focus will turn to research in which similar studies relating to science discourses in the public sphere and the transmission of knowledge are addressed. Following will be an outlining of the theoretical approach taken in the current study, Foucauldian discourse analysis, along 
with a description of the specific methods used. After a comprehensive analysis of the data central to this study, the findings are discussed and concluded with possible implications for future research.

\subsection{Background}

The global pandemic that seemingly stopped the world in 2020 forced us to consider the importance of scientific data with a level of urgency and desperation that was previously unknown to a large part of the global population. We saw the world watching numbers rise, wondering what they could tell us, both about our current state and what our future would look like. We also saw politicians, doctors, scientists and a variety of experts reiterate those numbers and attempt to explain what their implications were in terms of how human behaviour would be changed, and what the consequences would be if it did not. While the term 'unprecedented' became the hallmark word to describe the human experience of the Covid-19 pandemic, it does not apply to the challenge that has faced science researchers for years: communicating the implications of their findings to the general public. There is the obvious challenge of explaining scientific information to those who lack an informed background understanding of science in general, but this form of translating is not the only issue and hand; as the implications of findings from scientific research often advise changes to human behaviour, the public response to the suggested actions is inevitably varied. Moreover, the interpretations of scientific knowledge by those outside the science world are becoming increasingly biased as a result of the politically and socially polarized public debates that surround much of the research findings in question. This divided course of information transmission has impacted how several issues, including climate change, vaccines and health 
recommendations, are accepted by those who make up the general public, but it is the heightened accessibility of the debates surrounding these issues through social media platforms that has further complicated the nature of these discussions. Particularly in a domain such as Twitter, where doctors and scientists are using the same discursive medium as politicians and conspiracy theorists, questions of who and what to believe are ubiquitous. What the debates on this platform indicate, aside from the fact that opinions are endlessly varied, is that scientific data may not hold the same level of knowledgebased authority in the public sphere that it once did.

Upon the consideration for the communication of scientific knowledge in academic communities and the public sphere alike, it is evident that the presentation of research findings through the use of statistics is common practice. Statistical data representation serves as symbolic action that operates in a diverse array of forms based on the contexts in which it is used. In their science-based, academic origins, statistics are most commonly used as a direct representation of research findings resulting from rigorous experimental practices. In the public sphere, most notably in prevalent online platforms, the representation of science statistics by public actors often serves as evidence for what they believe to be factual based on their understanding of what the science research means. What can be derived from this understanding is that regardless of how science statistics come to be, their function both changes and is changed by the context in which they appear. In any case, the presentation of statistical data embodies the intended transmission of a perceived truth by those who present them.

There is a degree to which we are all convinced of certain truths, based on our experiences and worldviews. In my case, I was certain that by taking university courses I 
was expanding my awareness of the world through what was presented in academic research. This in mind, I was somewhat surprised to discover that the findings of academic research are not quite accepted the same way in the public sphere as they are in academia, nor are they as reflective of the real world as I had initially thought when I started working for a farm in the summer of 2017. In a casual discussion about climate change with the farmer I worked for, not only did I come to find that he did not believe the scientific research that provides evidence for the threats associated with the climate crisis, but he also resented it. After a few months working in rural Ontario, I was able to see that this apparent disdain for academic research findings in general was a rather common sentiment amongst those in the farming community. I was, at first, confused by their mentality, especially considering the potential negative impact on their livelihood as the result of the climate crisis. What I came to realize, though, is that we were working with entirely different interpretations of climate science data and that they were just as convinced of their version of the truth as I was with mine. The experience led me to question what this meant for all scientific research findings and to consider the existence of other groups that are defined by a shared perspective on how they interpret science data and what they might consider to be the 'truth'.

Shortly after my time on the farm, I worked as a teaching assistant for a secondyear engineering course for which the purpose is to encourage the effective communication of the students' knowledge to those outside their discipline, and the general public more broadly. Witnessing firsthand the challenges involved with the reframing of the students' specialized knowledge in a way that would make sense to those who know nothing about it or the theoretical understandings upon which it is based, 
the root of misinterpreted scientific knowledge became more apparent. Part of the acceptance of hard evidence from the sciences relies upon having faith in the experts who produce and interpret the findings. While, in theory, relying upon these experts would be our best means of arriving at understandings as close to the 'truth' as possible, a universal agreement on that notion is nonexistent. My experience with the farmers provided a modest example of this predicament, but it comes as no surprise that with the amount of highly accessible representations of scientific information online, there is a broad base of similar cases to explore.

Indeed, there are numerous approaches one could take in an investigation of reproduced scientific knowledge in public, online domains. Instances of crucial information being spread through these means have created a situation that brings together the sciences, representations of social and political positioning, and an endless variety of contextual factors that influence how the information is understood and presented. The resulting public arguments taking place in the online domains could be viewed through a variety of disciplinary lenses, from political science to sociology, anthropology to communications and more. There are several advantages of approaching this exploration from a discourse analysis perspective: (1) the nature of discourse analysis allows for the consideration of multiple factors, as opposed to being constrained to a single one of the aforementioned contextual factors; (2) the flexibility of discourse analysis allows for the research to be guided by the aspects that stand out as most significant, allowing for findings that accurately reflect the real discussions being carried out; and (3) by viewing the transmission of information as a conversation, the ability to 
observe how the initial information changes based on the processes it goes through is provided.

These features of discourse analysis, in combination, can also help to justify the fairly broad scope of the current research endeavour; although any given aspect of the observed phenomena in this study could technically warrant its own analysis, the overall aims which seek to examine how the statistics operate in different contexts require an approach to research that can follow these numbers wherever they go. With the goal of observing the transmission of information between different spheres of knowledge, limiting the chosen statistics to a single context or limiting the overall group of data to a single set of statistics would not do justice to the research aims, and ultimately would confine the discussion to focusing on a specific topic as opposed to allowing for the observation of broader information transmission trends. By including several different areas of scientific research and associated public arguments, we will have a better chance of explaining how and why statistics function the way they do through the means of comparison, rather than making assumptions based on factors that could be specific to one issue as opposed to the prevailing characteristics of the discourse situation.

Why Twitter? In short, the analysis of tweets provides us with data that shares common boundaries, or it is the closest we may come to comparing 'like for like' in this type of analysis. The limited character count imposed by the platform allows for the observation of language use that adheres to a shared set of guidelines. While there are several other online platforms where these public arguments are carried out, comparing a 2,000-word Facebook post to a 200-character tweet would further broaden and complicate a study that already includes a complex assortment of information. 
Having put forth the intentions behind the current research endeavour, along with some justifications for why its specific features have been chosen, the focus now shifts to outlining some of the relevant academic literature backgrounding this study in chapter 2 . Chapter 3 provides an overview of the theoretical framework underpinning the study, followed by a description of the specific methods taken in chapter 4 . Chapter 5 includes the three-part analysis central to the research, which prompts the discussion in chapter 6 . Finally, the thesis is concluded in chapter 7. 


\section{Chapter 2: Review of Literature}

The following review of literature, similar to the scope of the current research in general, is intentionally broad, though organized with specific intention. To underpin a research undertaking for which the content is intrinsically connected to the social perceptions of scientific knowledge, the discussion begins with an overview of discoursal perspectives for how scientific knowledge is produced and reproduced, with emphasis on its academic origins and some developments in the field in recent history. Moving from the epistemological focus that concentrates on the production of the focal knowledge and onto discoursal phenomena that aim attention at the reproduction of that knowledge, the discussion pivots to provide the study with background information relating to recontextualization and rhetoric. As put forth in the preceding chapter, an integral aspect of the current research is that the social and political contexts in which the analyzed discourses are functioning have significant impact on the discourses themselves, as does the medium upon which they are carried out. This feature necessitates an overview of the particular manner in which those contextual factors impact the discourse, and how they have been addressed in previously published research. Concluding the current chapter of the study, three relevant studies in climates change discourse are explored for their connections to the topics discussed prior.

\subsection{The Production and Reproduction of Scientific Knowledge}

Attempts at tracing the transmission of information between different spheres of knowledge account for a broad base of research that explores various academic, public, and political discourses. At the foundation of the current study is the research concerned with social studies of science; more specifically, the means through which scientific 
knowledge is and has been constructed throughout its recent history, as explored by discourse analyses. Contemplations of what constitutes fact frequently lead to the consideration of science and its empirical roots, rendering the research that explores this specific type of knowledge-making not only a valuable foundation of information, but also a necessary basis upon which the analysis of statistical data in modern, public spheres can be built. The intended objectivity and authority of knowledge derived from science-based research and the related disciplinary discourses is, quite clearly, contested in the public sphere; however, the general lack of consensus surrounding the validity of scientific claims in public discourses is reflective of how the knowledge-making process in the social institution of the sciences has developed over time.

The representations of scientific facts as we understand them are, at their core, descriptions of scientific activities. Research concerned with how these scientific activities are described has been driven by the questions of how the descriptions are represented as literal and factual, and how individual scientists develop their descriptions within the framework of legitimate science - a framework that necessitates researcher impartiality and an adherence to disciplinary rules (Potter, 1996, p.19). Anchoring traditional scientific research and its intended production of fact is the process of observation. Mulkay (1979) outlines a sociological perspective of science in which knowledge from fields of science is: (1) unique in an epistemological sense, in that it is the product of controlled and rigorous procedures; (2) representing of the physical world with accuracy and completeness; and (3) an objective report free of bias and distortions from personal and social factors (Mulkay, 1979, p. 64). 
While, in theory, an observation-based empirical framework within which scientific knowledge is created suggests that objective presentations of fact are possible, Potter (1996) highlights two significant problems with the legitimacy of scientific knowledge derived from observation; the first, and most often discussed issue, is that of varied perception in the case of observations. It is not only true that variance in perception by individual researchers has an inevitable influence on the representation of their findings, but there is also a level of distortion resulting from the written discourse through which the knowledge is communicated. Despite researchers adhering to the most rigorous and controlled practices in their studies, the produced knowledge is not developed without some level of association with previously existing disciplinary knowledge. The intradisciplinary connections from one study to the next are not limited to what exactly is being researched or how the studies are structured, rather the written discourse in which scientific knowledge exists prompts the categorization of ideas and beliefs that govern what the science community considers factual. As the researchers operate within this disciplinary discourse, their findings can be seen as dependent upon pre-existing scientific knowledge as opposed to bearing total neutrality.

A second and more specific issue with the observation-based approach to empiricism within the sciences concerns the tools with which the research is carried out; it has been pointed out by a variety of philosophers and social scientists that the functioning of these tools is dependent on the theories that are assumed through their development. In other words, any observation made using a specific apparatus is working on the presupposition that all theories involved with how the apparatus functions are 
factual, therefore there is an added layer of assumptions upon which the findings are built.

The theorization surrounding attempted objectivity and the representation of scientific data as being free of any personal or social bias has long been contested. While it is still the case that research findings from the science fields are viewed in both public and academic spheres as being rooted in trusted, rigorous empirical processes, the consideration of the theoretical assumptions upon which the findings are based allows for the view of these findings as similar to those from any other academic discipline: the product of a community's activities and accepted beliefs.

The perspective that views the sciences and their related findings as a community practice is not limited to consideration for the scientific activities of the community in terms of how the research is carried out, instead it includes the more intangible and conceptual inquiry of how findings are regarded in terms of community beliefs. The scientific "web of belief" (Potter, 1996, p. 22) presents an additional realm by which the seemingly objective, empirical development of scientific claims is critiqued. In the assessment of the scientific web of belief, the conflicts of fact acceptance within the science research community are highlighted; by proving theories previously accepted by scholars it is more likely that a researcher's findings will be accepted than if they were to deviate from the original findings and attempt to disprove them (Potter, 1996, p. 23). Potter's (1996) discussion of this predicament brings into focus the impact of the community's compliance with what they consider theoretical and ideological truths, and their impact on the type of research that is conducted within the discipline. 
Has the threat of scrutiny from members of science communities prevented attempts at conducting research that contradicts widely accepted theoretical claims? Moreover, does knowledge of this research-determining factor further delegitimize the claims of objectivity as discussed in the conversation surrounding observation-based empiricism? These questions can be contemplated with various overarching theoretical assumptions, and can be applied in several contexts. For the purpose of clarity in an issue that is indeed complex, application of the Quine-Duhem theory as it relates to beliefs held in the science community has been a central focus in several studies exploring the philosophy of scientific knowledge. In Gee's (2016) exploration of the frameworks that underpin discourse analysis, the theory is employed to expose the ways in which the Quine-Duhem theory "sets limits to empiricism" (Gee, 2016, p. 344). By conceptualizing the beliefs held within science communities as a network of previously established assumptions, the degree to which all claims are connected to that network becomes clear: the influence of a belief network on the uptake of new research demonstrates the powerlessness of a single study or claim in relation to the broader network. The point at which subjectivity in scientific empiricism is most obvious from the belief network perspective is when a pre-existing and accepted claim is disproven, as it becomes unclear whether the new claim is wrong, or if there is a falsehood within the assumptions from previously accepted claims upon which the new research is built (Gee, 2016, p. 344). Although the theory (1962) itself suggests that no single claim can either verify or falsify itself, it does not account for the claim as external to the overall network, rather it considers new findings an addition to the broader network in a way that the network evolves over time, getting closer to the "truth" (Gee, 2016, p. 344). Conceptualizing 
construction of scientific fact with consideration for the network in which it develops allows for a view of empirical evidence in the science fields that presents theories and assumptions in the network of belief as separate from observation. This division allows for disciplinary knowledge to evolve through a network that is fluid in nature, and does not necessarily discount specific claims but instead allows them to guide future studies and reconsider previous ones. Potter's (1996) perception of the Quine-Duhem theory in relation to the construction of scientific knowledge differs from that of Gee (2016) in that it emphasizes the ability of a claim to pressure the entire network until researchers have no choice but to re-organize the network. This representation of the theory allows a crucial aspect of the network to be considered: it is constantly adjusting; the adjustments are both the result of new claims from observation and developments in the underlying theories (Potter, 1996, p. 23).

Extending the concepts proposed by the Quine-Duhem theory, philosopher Thomas Kuhn outlined a model for scientific knowledge construction that is rooted in community practice. The previously discussed network of beliefs, even with its various interpretations and descriptions, remains somewhat of an abstract explanation for how scientific knowledge is produced and accepted within science communities. Kuhn's analysis of what he coined the Structure of Scientific Revolutions (1970) proposes that the beliefs do not exist externally to real practices, nor do they remain a conceptual entity that has little impact until a theoretical reorganization is prompted; Kuhn's theorization of the belief network is one that places the theories and beliefs in every aspect of research practice - from the design of the studies to the observation procedures to the communication of findings. Where the Quine-Duhem theory suggests that the belief 
system is in a constant state of adjustments, Kuhn proposes that the network carries on with what is considered the expected set of standards as agreed upon by those in the science community until there is enough evidence against the fundamental theories that the whole system must be changed.

Placing Kuhn's beliefs about how the scientific belief system evolves in a discernable context, his (1970) analysis explains the discussed forced revolutions in paradigm as being prompted by "crisis" (Kuhn, 1970, p. 74). Emphasizing that researchers in the science community will carry on doing "normal science" until there is sufficient evidence that forces them to adjust the structure of fundamental beliefs, he states that: "retooling is an extravagance to be reserved for the occasion that demands it" (Kuhn, 1970, p. 76). Considering this notion in relation to the previously mentioned theories about scientific knowledge construction, Kuhn brings into focus the reluctance of the science community to have a shift in paradigm in a way that challenges the implied objectivity of the observation-empiricism model and the inferred receptiveness to adjustments outlined in the Quine-Duhem theory. Kuhn takes an alternative perspective to that which suggests research findings are tested against the world itself through observation and theorization, and puts forth that the science tests itself within the science community, conducting research that is in line with the accepted theories. For those accepted theories to change, he suggests, there must be new theory deemed sufficient enough to take its place: "The decision to reject one paradigm is always simultaneously the decision to accept another" (Kuhn, 1970, p. 77).

Philosophical and social theorizations about the construction of scientific knowledge and, through that, the production of "fact" have differed how it is believed 
that the information comes to be, and the level of objectivity and therefore trustworthiness associated with findings. Where the concepts show similarities with one another, though, is in their connections made to some form of community. Despite the seemingly isolated observation-based studies intended to demonstrate a lack of bias, the observation view of scientific research discusses practices that rely upon a broader system of accepted theoretical and practical standards established by those in the community before. The viewpoint rooted in the Quine-Duhem theory emphasizes the opportunity for adjustments to the belief system being made only through community consensus while minimizing the potential impact of a single claim. Finally, Kuhn's paradigmatic approach is one of the most unambiguous characterizations of the degree to which scientific knowledge construction is dependent on the community that produces it, as he suggests that the type of knowledge being produced is more so a product of testing against community norms than it is testing against the world itself.

A combination of all discussed theoretical propositions might consider scientific knowledge construction as being representative of an ongoing conversation more than it is a definitive set of unchanging truths. While in regard to the science world this is a notion that allows us to imagine the knowledge derived from scientific research as being the closest thing possible to the truth, the issues surrounding objectivity and reliability become magnified when the information is transmitted from within the science community to the public sphere. As it relates to the current investigation, it must be emphasized that the public perceptions of science have a significant impact on how findings from the science fields are accepted in public realms. In this case, it means that the purposes for and approaches to statistical data presentation are likely to have a varied 
impact in different contexts, which is an element that will be critical to the analysis of the current study's data. Having insight of how scientific knowledge is constructed is an appropriate foundation for the current research, however an informed overview of the processes involved with the transmission of that knowledge is essential.

\subsection{Recontextualization of Knowledge}

Be it information derived from empirical research in the science fields or that of any other discourse community, there are inevitable challenges in how information is shared across discoursal boundaries. The previous discussion of scientific knowledge construction outlines a complex set of features that account for an already complicated set of circumstances, making it no surprise that the transmission of that knowledge bears further difficulties. A variety of issues are known to arise in these discourse boundary crossing scenarios, specifically in terms of maintaining the accuracy of the claims put forth from the source, and the effective representation of the researcher's intended purposes. Perhaps the most critical aspect of the transmission of information between any spheres of knowledge is the process of how that information is reproduced in different contexts. Perspectives informed by discourse analysis bring into focus the degree to which no information is free of context, which points to the impact that contextual factors bear when it comes to both the information itself and how it is perceived when removed from its original conditions. This exact process and its involved complications are central to the current research; as statistics are traced from their contexts of origin to those of public spheres and examined for their durability, the analysis of the conditions in which they exist will provide the most accurate as possible explanation for how and why information both impacts and is impacted by context. Theories of and studies in 
recontextualization are at the core of this social and discoursal predicament, and are thereby essential to the current research.

At the base of recontextualization is an understanding of contexts as they are related to discourse and, in this case specifically, texts. Per Linell's (1998) work on recontextualizations and discourse boundaries provides a comprehensive description of what constitutes context in terms of its features, stating that they draw on a variety of contextual resources, including: "prior discourse, concrete physical environments, people (and assumptions about people) with their interpersonal relations, various kinds of background knowledge, situation definitions (frames), models of topics talked about, etc." (Linell, 1998, p. 144). Where these contextual factors have the most relativity to recontextualizations and, more broadly, the current research, is in their association with discourse; Linell asserts that any discourse is situated within the framework of these factors, and that an analysis of any discourse operates on some degree of background assumptions about these contextual resources (Linell, 1998, p.144).

Identification of contextual resources is a valuable step towards a deeper understanding of the factors that influence discoursal outcomes, but an examination of discourse that has crossed discourse boundaries and, with that, differing matrixes of context, sheds light on just how malleable any information within the process of recontextualization. Linell identifies the influence of context resources a core component of this process, suggesting that a discourse cannot be removed from its context of origin and placed in a new one without the risk of its interpretations being shifted (Linell, p. 144, 1998). In short, Linell defines recontextualization as a process of relocation - the transfer of information from one context to another, and the transformation of the 
information there within. While, by definition, the concept can be seen as a straightforward one, recontextualization carries with it a complex array of contributing factors and a variety of possible outcomes. Going forward, as several examples of recontextualization are explored, it is worthwhile to keep in mind Linell's most explicit statement on the process, that: "recontextualization is never a pure transfer of a fixed meaning" (Linell, 1998, p. 145).

An area of focus concerning recontextualization that is exceedingly relevant both in this research and the current social climate is that of the intertextual boundary-crossing from professional to lay discourses. Linell's (1998) research describes this particular interaction of texts as a clash of perspectives resulting from the differences between the respective groups' ideologies, background knowledge, perspectives, and approaches to information uptake based on cultural and ideological factors (Linell, 1998, p. 148). The advantages of examining contexts within a cross-boundary text interaction are apparent when seeking a more informed understanding of a piece of discourse, yet it is also a process that exposes the highly complex and multilayered nature of recontextualization and its vast potentiality.

Drawing on Bernstein's (2000) models for the specific categories in which different types of recontextualizations can be realized will assist in narrowing the focus of the, at this point, broadly described process that is recontextualization. Bernstein's models illustrate that there are several more contributing factors to a given recontextualization process than a mere consideration for the contextual resources previously addressed. Instead, as Bernstein suggests, the recontextualization of information is always situated within a broader set of social structures that determine how 
the process functions based on the access to social power by those involved in the discourse (Bernstein, 2000, pp.41-45). While Bernstein's theoretical assumptions were initially focused on recontextualizations in pedagogy, his concepts rooted in social power structures can be and have been employed to explain the process in different contexts. Bernstein's frame of reference allows us to recognize that recontextualizations are impacted not only by the type of information being reproduced or the contextual resources of the individual actors, but instead that the process is one that is shaped by social aspects of power and the accessibility to a discourse pre-existing to the recontextualization process.

One particular adoption of Bernstein's seminal theory that displays the significance of ideological frameworks on how information is produced and reproduced is Jackie Marsh's (2007) study that examines the changes in literacy pedagogies over a ten-year period; where the study becomes relevant to the topic of the current research is in how it draws on Bernstein's (2000) premise that there are official recontextualization fields (ORF) and pedagogic recontextualization fields (PRF), wherein ORFs are created by the dominant discourse and PRFs include the actors involved with reproducing (in our case, rewriting) information derived from the ORFs (Bernstein, 2000, p.115).

Marsh's findings indicated that evolutions in the PRF were ahead of what the ORF was producing in terms of how the real-world requirements for literacy differed from what the official sources provided. These findings cast light on the discoursal disconnect between the two fields in general, and are indicative of how similar social issues necessitate research guided by the principles of recontextualization. The applications of the fields in Marsh's study are unambiguous as she deals directly with 
pedagogical practices, but their relation to the current exploration requires additional explanation; the official fields are evidently those from which the initial data originates, while the concept of the pedagogic field prompts the acknowledgement of a discourse community crucial to the reproduction of data: authors, journalists, policy makers, and any other social actors with access to a substantial audience, and who are considered to have some level of knowledge authority. The PRF then, in this sense, points to an element of recontextualization that calls for further investigation due to the control the members of this field have over the ways in which data is recontextualized for public audiences.

For examples of how the pedagogic rhetorical field functions in observable contexts, we can revisit the previously discussed interactions of professional-lay discourse. An analysis covering the recontextualization of numerical values in clinical practice (Adelswärd \& Sachs, 1998) exhibits a real-world scenario in which numerical data is being recontextualized for hospital patients by nurses. The translation of information, as it is termed in the study, is one "from epidemiological findings into clinical knowledge and practice and then into lay experiences of health and highly personal thoughts about one's own possible future disease" (Adelswärd \& Sachs, 1998, p. 192). Considering that the epidemiological findings would be derived from the ORF, the clinical practitioner holds the role of data interpretation and reproduction through the PRF. What the study reveals in its findings is that, in every case, the patients asked for elaboration on the numerical values the received because they were unable to comprehend their implications without further explanation, demonstrating that the biggest challenge was the patients' inability to interpret decontextualized numbers (Adelswärd \& 
Sachs, 1998, p. 196). The study assists in the realization of just how crucial a component the communication from the professional field is within the overall professional-lay interaction, and also points to the vulnerability of numerical data within these interactional contexts.

The included literature supporting a background of information about how recontextualization functions and its function as a discursive strategy more broadly has demonstrated not only how impactful it can be in the transmission of information between various spheres of knowledge, but also how central it is to the nature of the explored discourses within the current study. Indeed, the brief overview of literature the studies scientific (medical) information being actively recontextualized is useful background in terms of its relevance, a main takeaway from this discussion should be the consideration for context and how it exists in conjunction to the process of recontextualization. The included data addresses multiple instances of discourse, and with that it carries multiple contexts; attention to this condition inevitable shapes how the data is to be explored, and ultimately what can be discovered about the impact of contextual factors on statistical data as it exists in the online public sphere.

\subsection{Rhetoric as Symbolic Action}

At the core of this research endeavour is the shared understanding by those in the science community and the public alike that numerical data has the capacity to persuade. It is in uncovering the intentions behind, approaches to, and effectiveness of that persuasion that will allow us the opportunity to gain a more informed understanding of what exactly is occurring in the transmission of information from the science community to the public sphere. This makes it imperative that this study is backgrounded by a 
consideration for rhetoric and the role it plays within the discourse situation focal to the current research. Moving from an analysis of recontextualization as it relates to the discourse in question and onto the similarly important aspects of rhetoric, the following section serves to indicate the connection between these two discoursal processes, but also highlights the need to address some of the main features of rhetoric on their own. With the broad base of research that accounts for theories of rhetoric in discourse studies, the discussion could very easily stray into territory not entirely necessitated by the aims of the current research. With that, specific aspects of rhetorical theory in discourse studies have been selected based upon their relevance to the goals of the current study. Considering that numerical data is focal to the research endeavour, an appropriate starting point for this portion of the literature review is to explore the conception of rhetoric as symbolic action.

Rhetoric is understood to many as the use of language to persuade, but within discourse studies it takes on various conceptions that bear connections to the many social and contextual factors often considered by researchers in the field. I will introduce one of the more prominent conceptions - rhetoric as symbolic action - with a quote from Stillar (1998) whose framework for rhetorical analysis draws on the work of Kenneth Burke: "the nature of systems of symbolic resources not only enables symbolic acts to be recognizably meaningful but also powerfully constrains symbol users by circumscribing conditions and consequences of their acts" (Stillar, 1998, p. 58). Systems of symbolic resources, as put forth in the literature, can be understood for our purposes as language and all that language encompasses- including written text, spoken word, numbers, images, and so on. 
We can exemplify this notion by considering that the discourses of science data, as they exist both within science communities and the public sphere, function within a system of symbolic resources of its own- one that draws on recognizable language and processes to create meaning. This process of meaning making has been addressed in the previously discussed context of scientific knowledge construction and recontextualization, and is made more apparent through its explanation as a rhetorical tool. The latter point of Stillar's quote is also significant for how it brings into focus the outcomes of engaging in symbolic action, in that 'symbol users' either adhere to the constraints of the symbolic system or face certain consequences. Recognition of this circumstance brings us to consider that rhetoric functions not only as an isolated symbolic action in the theoretical sense, but also that it produces and explains real-world rhetorical situations in which we very often find ourselves.

To this point, I have referred to the discourses focal to this study as discourse situations, and upon exploration of rhetorical theory it becomes clear that these discourse situations are very much rhetorical situations as well; Stillar suggests that the situations in which texts occur in general are inherently rhetorical in nature (Stillar, 1998, p. 59). Stillar's study uses an anecdote describing a student's note to their professor asking for their late paper to be accepted as an example for how a text performs the rhetorical function of persuading the reader to act in a specific manner, or with how a text is written with a particular purpose. The rhetorical situation in which the discourses of this study exist can be considered with a similar perspective: the use of statistics in public argumentation is, in itself, an attempt at persuading the audiences of those arguments to accept the statistics as proof for whatever the argument may be. The common 
understanding of the purpose for statistics in this rhetorical situation points to another feature of the theories of rhetoric that we are currently dealing with - the function of rhetoric is inherently connected to the function of language more broadly (Stillar, 1998, p. 59). Burke encapsulates this shared function with an explanation for what lies at the core of both language and rhetoric, suggesting that they both act as "a symbolic means of inducing cooperation in beings that by nature respond to symbols" (Burke, 1969, p. 43). By acknowledging that there is an underlying attempt to prompt cooperation with the rhetorical use of language, we are provided the opportunity to explore the aspects of a given rhetorical situation in a way that allows for an indication of the motives behind and purposes for the analyzed texts.

We have addressed that the situation, with all its purposes and contexts, is a worthy point of investigation when seeking a better understanding of the rhetorical aspects of the discourse in question, but it is essential that the audience of a text be identified and contemplated for a fully developed analysis of a given rhetorical function. This consideration does not have the sole purpose of indicating a contextual feature of the discourse itself, rather it also allows for an understanding of the purpose for a text being written based on what we can learn about the audience. From this perspective, it becomes clear that it is not just the author of a text who has the ability to persuade, but instead that the audience of a given text has a significant influence on what the author puts forth. As stated by Burke: "If, in the opinion of a given audience, a certain kind on conduct is admirable, then a speaker might persuade the audience by using ideas and images that identify his cause with that kind of conduct" (Burke, 1969, p. 55). Concerning the audiences within the data for the current study, it will be useful to identify any common 
themes amongst them to gain a more developed understanding of how the recontextualized versions of the statistics are functioning. An awareness of audience within the science community is another essential aspect of the analysis, especially pertaining to how the statistics are presented in their original form in the academic journals. While, of course, it will not be possible to explicitly identify the audiences as a result of the widely public nature of the data, gaining any information possible about the roles of the social actors involved in the discourse will suggest the audience for which the commentary is intended, and with that the purposes too will become more evident.

It has been made clear that the exploration of rhetoric is an essential aspect of this particular discourse analysis, specifically for how it allows for the consideration of factors that make seemingly objective 'fact' non-neutral in its online public representation. The connections between rhetoric and recontextualization are significant in that the analysis of both can contribute to a clearer picture of each facet, and with that bring us closer to a realistic idea of what is actually occurring within the discourse. At this point, the case has been made for the value of including context focused perspectives within discourse analyses, especially considering the wide array of social factors contributing to the discourse in question. It should also be acknowledged, though, that rhetorical analysis has the capacity to provide more than just a set of assumptions about what is behind certain discoursal features, rather it can also provide insight to the values and worldviews of those engaged the discourse. Nystrand \& Duffy (2003) characterize this connection between worldview and rhetoric with his suggestion that rhetoric is: "The ways that institutions and individuals use symbols to structure their thought and shape their conceptions of the world" (Nystrand \& Duffy, 2003, p. 40). It is this discernment 
that prompts the following area of focus in the current review of literature: a regard for the social and political identities that are both produced and reproduced through the online discourse at hand.

\subsection{Political Ideology and (Social) Media Discourse}

Although there are various definitions and understandings associated with the term 'ideology', for the purposes of the current study, we can consider it to describe a shared set of beliefs. Exploring the effectiveness of traditional discourse analysis approaches to indicating evidence of ideology representation in media texts, Carvalho (2000) asserts that the intricacies involved with determining which conceptual tools are employed for the representation of ideology and rhetorical knowledge requires a comprehensive approach, in which the scope and nature of the data is chosen specifically to suit the research goals (Carvalho, 2000, p. 36). The suggested approach is a departure from those which prioritize a goal of objectivity, in that the (2000) study provides an example for how the ideology, as it is represented in text, is more effectively revealed by taking into consideration the involved social actors, political interactions, and the critical moments in which those aspects are in operation (Carvalho, 2000, p. 37). The findings of the (2000) article are highly relevant to the one of the questions central to the current research: how do social and political ideologies, from a rhetorical perspective, influence the recontextualization process? Moreover, how are these ideologies discursively reconstructed through social media texts within the recontextualization process? Carvalho's analysis highlights the connection between assigned meanings and the realities they suggest (Carvalho, 2000, p. 37), and demonstrates how discovering those connections requires the researcher to be informed by social and political contexts in 
which the mediated discourse exists - these factors are critical to our interpretations of recontextualizations.

Carvalho, whose work appears multiple times in media-based analyses of ideological production and reproduction in media texts, provides a second discussion relevant to the current theme with her (2008) study, in which the discursive strategies employed within media texts are indicated. The text outlines how ideology and its textual representations are, in a politicized context, inherently related to rhetorical tools (Carvalho, 2008, p. 169). The rhetorical role of social actors, journalists included, in connection with the messages they deliver through written text is presented as a form of discursive manipulation (Carvalho, 2008, p.169). The intended meaning of the term points to the purposes of the involved actors in the explored texts, specifically that their positionality is one in which they aim to achieve a goal with their language use (Carvalho, 2008, p. 169). The claims made in the (2008) study inform our understanding of ideology representation in mediated discourse for how it demonstrates the lack of neutrality on behalf of the actors connected to a text, and in that is indicative of discursive ideology representation being the function of a specific goal set. This notion is one that ought to be considered throughout the current analysis, especially in the examination of who is involved with the transmission and reception of discoursal knowledge, and what their possible aims are.

The implications of the previously discussed Carvalho $(2000,2008)$ studies on the ways in which ideological representation in media text has the capacity to resonate with and therefore influence audiences brings forth particular issues regarding the responsibilities of those who mediate news texts; these actors may also be considered to 
act as the PRF, as previously outlined. With the ability to operationalize the contextual resources known to their target audiences and, therefore, manipulate discursively, the social actors and journalists involved with meaning making in the media have an apparent degree of power with their recontextualizations of data from the official fields. Considerations for this structure of knowledge spreading have resulted in studies that suggest a necessity for changes to the current mediated discourse model, specifically that to achieve democracy in media discourses, emphasis should be placed on connecting politicized issues with the personal experience, and to support the general audience's critical approach to opinion forming (Chouliaraki, 2000, p. 309). Research indicating the specific ways that media discourse can become more democratic in nature speaks both to the potential for media discourse to influence, and also to the possibilities of reshaping the transmission of information and ideological rhetoric with the findings from studies that recognize these social and political factors.

While, up to this point it has only been touched on briefly, the impact of political ideology in recontextualized information can be seen in a variety of social contexts, but its influences should also be considered in relation to information from the science fields, as the focal data from these discourses is very often politicized once it reaches the public sphere. Focus on the media itself as the environment in which the questions of the current review can be explored have, thus far, driven the discussion to highlight the discursive elements within the structure of media and social media discourses. To deepen our understanding of the discursive construction of political identity through media text in general, however, the means through which identity itself is constructed discursively must be explored. Political identity must be considered as inextricably linked to ideology 
for the purposes of coming to conclusions that are politically contextualized; because when the surrounding discourses are not free from political ideology, neither will be the recontextualizations of the information they are focused on - not even those from the scientific research.

From an identity-based perspective, identifiable discursive ideas are discussed academic literature as being implicit reflections of more explicit ideologies (Blackledge, 2002, p. 70). This particular representation of ideology is an identification of the value systems that exist both within and externally to media and social media discourse. Thus, presented is another significant factor within the current discussion for how it suggests that audiences and social actors are often ideologically affiliated prior to engaging with political discourse in the media. While political identity is not expressed as fixed and unwavering, the literature identifies how use of specific linguistic features in media discourse serves to produce and reproduce pre-existing ideological affiliation through the participatory discrimination of groups based on their linguistic capacity (Blackledge, 2002, p. 84). In short, the literature demonstrates how the language used within media discourses constructs and maintains the identities of its audience, and is a key factor in how political identity is discursively constructed.

Ata a glance, the social, political, and identity-based components of the discourses at hand are detached from statistical data, and it is a common conception both within academia and in the public sphere that numerical findings exist separate from the mentioned contexts; herein lies a critical component of the research endeavour overall: not only does a connection exist between statistical data and real-world contexts, they are inextricably linked. Furthermore, it is the exploration of this connection that allows for 
more comprehensive understandings of the effectiveness of science research findings in reality, along with the opportunity to observe the discourses in ways that inform disciplinary conceptions of the implications associated with differing contexts.

\subsection{Science Data and the 'Death of Expertise'}

Thus far, the review of literature has taken a linear approach to describing issues and studies relevant to the current research. Beginning with an outlining of how scientific knowledge is constructed, through the lens of discourse studies, background knowledge for the information central to the study - statistics from science research - has been presented in a way that allows for a more informed perspective when considered alongside the described discoursal tools, recontextualization and rhetoric. The preceding discussion surrounding political ideology and new media indicates how all the previously discussed subject matter may be impacted when combined with the means through which the discourse takes place along with the social and political factors that influence that discourse. To complete the current review of literature, three studies that are reminiscent of the subject matter focal to this study are discussed, both to illustrate the connections between the topics explored thus far in the study and to demonstrate the value of a perspective rooted in discourse analysis when conducting research on these topics.

Three studies in particular by Smart $(2011 ; 2013 ; 2016)$ illustrate the distinct features that can be identified through the careful analysis of public discussions pertaining to data from scientific research and their related social significance. In these cases, the discourse in question is that which focuses solely on climate change data, though it provides a useful example for how to approach the similar discussions relating to other types of science data. The first study in question explores the formation of 
arguments by multiple organizations pertaining to climate change discourses and provides insight into how discourse groups or 'coalitions' can be grouped based on their shared sentiments as evidenced by the sampled discourse. Findings of the study reveal that the stances on climate change seemingly held by the organizations could allow them to be categorized as either viewing climate change and its consequences as a crisis requiring action, or as an issue that prompted skepticism regarding the impacts and necessity for solution efforts. Interestingly, the analysis displays that both coalitions formed their arguments in similar progressions, both operationalizing scientific claims, but presented contrasting representations of information from the fields of science they engaged with.

Upon closer inspection of the comparison between the two coalitions, the findings highlight another significant feature of how arguments are formed within the studied networks: the discoursal groups are evidently in contact with one another. The means through which arguments are formed on either side of the debate are indicative how claims made by both coalitions can be considered as a rebuttal to those made by the other. The claims made by a variety of experts are employed by skeptics and crisis believers alike, though the politicized nature of the discussion resulted in different rhetorical strategies on the specific variety of "expert" was used and which claims supported the predetermined goals of the coalition. In short, the coalitions both selected claims that catered to their argument, demonstrated common strategies in argument building, and could be seen to both influence and be affected by arguments from the opposing coalition. 
This first study highlights several features relevant to the current research. Primarily, by using Hajer's (2005) framework for 'discourse coalitions', the identifiable groups in the study serve as a representation for how the data is interpreted by public actors who have either developed or are engaged with a specific stance on the issue at hand, regardless of what the scientific data suggests. This illustrates the previously discussed connection between the social and political context of the issues focal to this study, and also demonstrates how those who engage with the data in question often approach their interpretations of said data with preconceptions based on the stance they are associated with.

Focusing on the public debate surrounding climate change, the second study for consideration by Smart (2016) seeks to identify which discoursal groups (or, as described earlier, 'discourse coalitions') exist in the web-based domain driving the public discussion, and the specific types of scientific "knowledge" relating to the climate debate are available to those groups based on the discourses with which they are engaged. The corpus analysis of public texts and science blogs used to represent discourses of environmental debate illuminate how eco-optimists, skeptics, and advocates all present contrasting claims in their crafting of publicly accessible versions of scientific understandings, and each attempt gain a knowledge-based authority over the global debate on climate change. A significant finding from the analysis relates to the medium of blogging, in that the actors involved, whether social or science driven, have the capacity to engage with the broader debate outside the suggested discourse coalitions; however, the discussed coalitions do create barriers to adequately informed public 
perceptions because of the highly contrasted versions of climate science that they package for the general public.

The findings of this study most useful for the purposes of the current discussion are those which indicate that what we may consider to be "scientific knowledge" does not carry a consistently accepted level of authority in its related public discussions. This point in particular brings into focus the importance of the beginning of this literature review and the exploration of how science knowledge is and has been constructed, and how the empirical standards through which science data is produced may result in the acceptance of certain knowledge within the science community but does not necessarily elicit the same confidence when presented in other spheres of knowledge. Another significant aspect of the 2016 study connected to the current review of literature is Smart's exemplification of how the discourse functions online in a way that allows for those involved to engage with arguments outside the specific debate, and the varied representations of the 'facts' relevant to the study as a result of this web-based means of information representation and debate. This feature of the discourse is a direct representation of the recontextualization of information for and by different actors. Earlier in the discussion, the overview of recontextualization and its roots in discourse studies included Linnell's (1998) suggestion that recontextualizations are not fixed and stable representations of original information, rather they are formed and altered as a result of involved contextual factors. The distinction made in Smart's (2016) study between social and science driven actors and the contextually varied factors they bring to their representations of data and resulting debates indicates the importance of considering 
how recontextualization functions and influences in the case of the several debates that are explored in the current research.

Finally, Smart's third study for consideration in this discussion (2013) focuses specifically on representations of science in the climate-change debate and brings into focus the degree to which rhetorical strategies allow for subjectivity in the public perception of science, based on which information is chosen and how it is presented. Contrary to the previously discussed studies that present the differences between discourse coalitions in the global debate over climate change, the findings of this particular research highlight the shared rhetorical tactics used by ideologically opposed groups to gain the trust of their audiences by emphasizing scientific authority. The article also presents similar findings to those of the previous studies in that although the rhetorical strategies are shared between advocates and skeptics, the reasoning behind their chosen knowledge representation is to either support their own argumentative goals or to undermine those of the opposing coalition. Considering the previously explored impacts of rhetoric as a tool in discourse, this study provides a clear example of rhetorical tools in action with how the contrasting versions of climate science are presented to the public, and how persuasion can function to divide those engaged with discussions centered on knowledge that was originally intended to be understood as objective fact.

Identifiably, each of Smart's studies demonstrate elements of discourse analysis that are considerably beneficial to our understandings of the discourses on which they focus. Moreover, they can be seen, in the context of the current research, as exemplifying the connections between the themes discussed thus far and the capacity for the forthcoming analysis to produce unique findings. Not only is it possible to combine 
knowledge pertaining to the construction of scientific knowledge with that of discursive strategies including recontextualization and rhetoric, and to ground said topics in a contextually informed frame of reference, but the intersection of these elements also serves as an effective underpinning specialized for the content of this study's analysis. It is at this stage, in Chapter 3, that the focus of the thesis shifts from being situated in the knowledge that backgrounds the current research, to indicating and justifying the theoretical lens through which the study's data is analyzed. 


\section{Chapter 3: Theoretical Framework}

A study that draws on such a wide variety of previous work from several different areas of discourse studies requires a specific lens through which the material can be observed. While the primary focus of the current research overall remains to explore the use of science statistics in the public sphere, the perspective from which statistics are viewed, in this case, requires a comprehensive delineation of theoretical approaches in discourse studies. Although the works addressed in the preceding literature review have provided a diverse and seemingly broad collection of disciplinary understandings, they share some similarities in terms of the theoretical perspectives that underpin them. Upon consideration for the commonalities that tie together the relevant studies, it becomes clear that the analytical strategies used are most effective when they are able to explore the content in a way that connects the language in use to the broader contexts in which it exists. It can be said that identifying the connection between language and its contexts is one of the primary aims of discourse studies in general, and this is certainly true in terms of the current research. This chapter begins with a brief overview of common practices and understandings within the discipline of discourse studies, then moves to discuss relevant theoretical conceptions underpinning research similar to the current investigation. Finally, the discussion will outline the effectiveness of Foucauldian discourse analysis, and justify its operationalization in this thesis as compared to the other approaches addressed in the chapter.

There are various dimensions of discourse and what meaning the term itself carries, but for the purposes of this research, we may understand it as the representation of social action, and as being inextricably connected the social contexts in which it 
exists. The approaches made possible by the diverse nature of discourse studies provide the unique ability to explore topics from several perspectives. Although this is one of the fundamental advantages of working within the discipline, it presents unique challenges when it comes to deciding upon the most appropriate theoretical perspective to take for a given study. This challenge exists for most analyses, but it is especially prominent in the case of the current study because of the factors that surround the data, and the overall aims of the study. Combining background knowledge of how the initial data, in this case the statistics from scientific research, is created along with the tools used to represent that knowledge in a different sphere of knowledge, this study has the potential to go in several different directions. To effectively answer the research questions, the perspective taken here must be less concerned with the how the statistics were developed or how they impact the science world, rather it should allow for an observation of how they are impacted as they travel through the spheres of knowledge and what that might tell us about the discourses involved.

Provided the term discourse has come to acquire such an array of different meanings, not only within discourse studies but also in the sense of common knowledge, it is imperative that its meaning as chosen for the theoretical usage in this study is clearly defined. From a perspective rooted in Applied Linguistics, discourse can be conceived as "language in use... [or] the relationships between sentences" (Pennycook, 1994, p. 117). This theorization of discourse was widely accepted as its primary meaning in the field of Applied Linguistics, prior to the increasing popularity of discourse analysis as an area of study. 
With the expanded knowledge and development of theory resulting from the advancements in discourse analysis came broadened and more varied understandings of what discourse could entail, as outlined by Pennycook: "first as 'a general term for examples of language use, i.e. language which has been produced as the result of an act of communication', and second - in contrast to grammar, which deals with clauses, phrases, and sentences - as referring to 'larger units of language such as paragraphs, conversations, and interviews"' (Pennycook, 1994, p.117). With those understandings of discourse shared by analysts, the foundational aims of discourse analysis are such that relationships between language use and the contexts in which they exist may be explored.

Discourse analysis, as it was first understood as a branch of applied linguistics, has not remained a clear-cut and unchanging approach to understanding language use that exists beyond the sentence. As more contextual factors came to be included in the analyses, so too did a variety of ideologically rooted perspectives that have guided research to emphasize the impacts of social and political factors on how discourses function, and what exactly can be observed about a given discourse when those factors are considered. A prominent area of study where this concept is exemplified is the field of critical discourse analysis (CDA). Where CDA differs from the initial applied linguistics sense of discourse analysis is in its underlying assumption that all discourse is in some way connected to social order. The relationships between language and society that are uncovered by a critical approach to discourse analysis are invaluable for how they have broadened the potentiality of research, but there are aspects of the critical approach to discourse analysis that render it not entirely appropriate for all research endeavours. A common position taken in CDA is that discourses are determined by the 
social, economic, and political factors considered by analysts; while this is true to some degree, it is a position that has been criticized for how its underlying models are often based on broad assumptions about those factors, leading to human agency and situationally specific characteristics being overlooked (Pennycook, 1994, p. 126). As much of the data gathered for the current study is public in nature, it is imperative that the social, political, and economic factors that guide critical discourse analyses be contemplated. Upon consideration for the aims of this study, though, it is also clear that an approach rooted in CDA is not the most effective means of observation in this case. While the early understandings of discourse as it came up in applied linguistics suggest a theoretical approach that would be too detached from contextual factors influencing the data, a critical approach would rely too heavily on assumptions about those factors and their possible impact on both the academic and public spheres.

At this stage, it is evident that a theoretical framework rooted in a contextually focused school of thought would be of the most value for the current purposes. A vast amount of comparable research in the field takes on a Foucauldian notion of discourse for how it highlights the social structures that determine numerous aspects of the relevant contexts, and has allowed for findings that are informed both by the discourses themselves and the factors that mould them. This combination is crucial in terms of the ability to view the current collection of data in a way that will provide more information about the discoursal processes involved rather than just the data itself.

On the other hand, taking a Foucauldian approach also mitigates the risk for assumptions about the involved populations that could alter the direction of the study to highlight the social experiences of those groups as opposed to making observation about 
how the statistics function from one sphere to another, which would be a possible outcome of taking a CDA informed approach. I have chosen Pennycook's (1994) discussion of the different meanings ascribed to discourse and the analytical approaches derived from those definitions for how he sums up the conflict I have just outlined; by using Foucault as a theoretical underpinning for discourse analysis, he suggests that the opportunity to engage in critical analysis without the bias of reductions and totalizations is provided (Pennycook, 1994, p. 126). Such an approach is, in this case, favourable because of the risk of reducing scientific knowledge to representing a single intention or opinion, alongside the possibility of observing the public sphere as a community as opposed to a group of separate individuals (totalizing). That said, it is also important that a middle ground is established in terms of taking a theoretical perspective that still allows for the observation of the social, contextual factors and how they might influence the data - another reason a Foucauldian approach provides the most appropriate means of analysis for the aims of the current study.

What constitutes a Foucauldian discourse analysis is somewhat difficult to identify, considering the wide range of interpretations of his work. Moreover, deliberations over whether or not studies that have taken a Foucauldian approach have accurately depicted his foundational knowledge have been the centre of discussion in several discourse analyses. In particular, Graham's (2011) exploration of this very topic points to the challenges involved with pinpointing how exactly one does a Foucauldian discourse analysis. The main barrier she highlights in terms of outlining this approach surrounds the futility of attempting to develop a methodology for "truth seeking". 
As previously discussed in the review of literature involved with the construction of scientific knowledge, it has been evidenced that for many areas of research, stringent methodologies that are in place with the intention of producing findings that are as close to objective truth as possible lend credibility to the research itself, and the fields of study more broadly. In the case of discourse analysis and language studies in general, Graham (2011) points out that such an aim is simply not possible, especially in regard to "a search for original meanings or personal agendas" (Graham, 2011, p. 667). While this notion may indicate significant limitations within discourse analysis, what Graham suggests is that instead of attempting to emulate scientific methodologies, discourse analysts must instead develop methods for research that are guided by a clear indication of what their objectives, limitations, and overall aims are (Graham, 2011, p. 667).

As this discussion relates to a Foucauldian perception of discourse, the aims of research need not be dictated by a pursuit of truth. Instead, a Foucauldian analysis is less concerned with the specifics of what is said or written and more focused on determining what the language does (Graham, 2011, p. 667). In the case of this study, the notion can be seen in how the guiding questions seek to explore what is happening with the transmission of information as opposed to what specifically that information entails. Graham also notes that a key feature of a Foucauldian notion of discourse prompts analyses that identify how discursive techniques lend themselves to the creation of meaning, as evidenced by the practices that are derived from the discourse in question (Graham, 2011, p. 668). This feature is key to our understanding of how the knowledge carried by the statistics impacts thoughts and behaviours in the public sphere and allows for the theorization of the degree of influence these numbers have in reality. 
Thus far, our discussion of Foucauldian discourse analysis has provided an identification for the common aims associated with this approach and has differentiated it from other related theoretical perspectives, but there is still the need to identify how this type of analysis can be carried out effectively. Graham's (2011) outlining of a Foucauldian approach to discourse analysis is culminated by a three-part framework in which she puts forth what she considers the main components of such an analysis: description, recognition, and classification (Graham, 2011, pp. 668-670). As the framework relates to description, it is suggested that the language central to this type of analysis must be both definable and locatable (Graham, 2011, p. 668). For Foucault, this notion is evidenced by his emphasis on the isolation of the language in question, and how it is to be examined only for "'the simple inscription of what is said' (Deleuze, 1988, p. 15) describing it, not as a linguistic unit like the sentence, but as 'a function'” (Foucault, 1972, p. 98). Here, a critical distinction is made in that the description of the examined language should not be described as a linguistic unit, rather it should be described for what that language does. In the case of the current research, this aspect comes to the forefront when the purpose or social function of the included data is indicated, prior to its examination.

In the case of recognition, the emphasis shifts from an identification of what the language is doing to how it is perceived, and what derives from that perception. Foucault (1972) characterizes this realm by outlining this particular purpose: "to analyse the conditions in which this function operates, to cover the different domains that this function presupposes and the way in which those domains are articulated" (Foucault, 1972, p. 87). This step is perhaps the most critical in terms of how the current research 
will be shaped, as the recognition of data in context will ultimately be the result of tracing its transmission between the included spheres of knowledge.

As a final feature Graham (2011) has included in the framework for Foucauldian discourse analysis, classification is described. Classification of specific language use is the closest this discussion comes to genre, as Graham points out how statements are defined by what else they are connected to, and that these connections are what keep a discourse functioning by reinforcing one another (Graham, 2011, p.671). I mention genre here, because the similarities between an approach rooted in genre and the classification of particular language use can be seen in how language that follows a certain type or form can be categorized through either approach.

I also wish to highlight why a theoretical approach entirely rooted in genre is not the best fit for the aims of the current study, in that it is only one aspect of the overall analysis and could, in isolation, lead to the over-generalization of what the analyzed language is connected to. From a Foucauldian perspective, though, the classification of the analyzed segments of language will allow for the ability to have a clearer understanding of their transmission, and for a more effective organization of the data. The mutual reinforcement suggested in Graham's consideration for the elements involved with this variety of discourse analysis is pertinent to our realization of how exactly the representations of statistics are connected to external factors, and what that might tell us about what meaning those representations hold and reproduce.

The conversation surrounding the theoretical perspective taken in the current study has, thus far, remained somewhat abstract albeit comprehensive. To portray how a Foucauldian approach to discourse analysis has been an effective tool in similar studies, 
there are several analyses we may consider. The application of a Foucauldian-centered theoretical framework in Smart's (2011) exploration of argumentation across web-based discourses exemplifies the appropriateness of a Foucauldian perspective when the analysis includes science data, different discourse communities, and the web-based setting in which the discourse functions. The analytical framework constructed for said study brings into focus the value of drawing on the work of Foucauldian theorists to construct one's theoretical lens, as the nature of studies which analyze factors that are inextricably linked to social phenomena prompts a means of analysis that can explore both the discourse itself as well as the social and political contexts that shape it.

In the case of Smart's (2011) study, he identifies two theorists whose interpretations of a Foucauldian analysis can be directly applied to the subject matter of both his study and the current one. First, by delineating James Gee's (2005) suggestion that the conversations which occur within given Discourses are a critical place of examination, it is made clear that the "discursive dynamics of public debate over controversial social issues" (Smart, 2011, p. 369) must be taken into consideration for a full picture of what exists beyond the analyzed language itself, or as Graham (2011) suggests, what it is doing.

Beyond Gee, the analytic framework of Smart's (2011) study is also informed by the Foucauldian-guided research of Maartin Hajer. Hajer (1995) points to the significance of the narratives that are constructed within discourse groups that he refers to as 'coalitions', which are made up of: “(1) a set of story-lines; (2) the [social] actors who utter these story-lines; and (3) the practices in which this discursive activity is based" (Hajer, 1995, p. 62). While the current research will not specifically be looking for 
discourse coalitions involved with the data, the concept is worth describing at this stage for how it is representative of what a Foucauldian approach can uncover, and for how it highlights the factors that are an inherent aspect of the public sphere data (story lines, social actors). The statistics that account for the data in this research endeavour do not exist in isolation from the factors that are brought into focus by a Foucauldian approach to their analysis, and it is with the consideration for those factors that a clearer understanding of the purpose and function of those statistics can be provided.

Having outlined what a Foucauldian discourse analysis entails while describing its features that are best suited to the aims of the current research, a final word on Foucauldian discourse analysis and its effectiveness in research focused on social media and media discourses will help to make the case for its appropriateness as the theoretical underpinning for this study. In a (2019) study that places focus on educational policy and how its related discourses are shaped through social media, Cecile Sam suggests that a Foucauldian discourse analysis is the best means of addressing discourses that occur on social media platforms for how it provides the researcher with the flexibility to account for the characteristics brought on by the platforms, while simultaneously exploring the discourse itself. She states that: "FDA can chronicle this [social media] discourse, with the ability to trace emergent trends and ideas. This analysis is powerful because it provides a way to explore policy through the lens of public opinion and belief. It is also flexible enough to adjust to new media" (Sam, 2019, p. 337). One of the intended purposes of the current study is to examine how the discourse around science statistics may differ from its place of origin (the academic sphere), and a key distinction between those spheres is the difference in domains for where the discourse functions. In order for 
us to be able to take into account the influence of the platforms on the discourse itself, the use of a theoretical framework that can, as Sam (2019) suggests, adjust to new media is essential to that endeavour.

It is, at this point, apparent that the current study seeks to explore a wide range of discoursal elements situated in a rather complex environment. The preceding review of literature covers a broad range of topics, but they all bear some relevance to the situation central to this research. It is through the use of a theoretical lens informed by Foucauldian discourse analysis that aspects of discussed previous research can be considered for their impact on the discourse explored here, while also allowing for a focused view of that discourse. As mentioned, the Foucauldian approach to this type of analysis is effective in part because of its flexibility; it does not work on assumptions about the structures or individuals involved and it also does not ignore the contextual factors that are inherently linked to the discourse. A Foucauldian discourse analysis has been proven to suit other studies with similar aims and content to this one, and it has evidently provided a useful lens for application to new media and social media. Combining this theoretical approach with the specific methodology outlined in the following pages, the scope of this seemingly broad research endeavour is narrowed. In chapter 4 , the specific methodology selected for the current study, as compelled by the reviewed literature and the chosen theoretical lens will be outlined. 


\section{Chapter 4: Methodology}

With the rise in various public debates over scientific knowledge, there is a growing necessity for research in how the related discussions are being carried out, and what exactly is being said. It is the combination of broadly accessible online platforms where the discourses are operating, and what appears to be a constantly increasing level of threat posed by the spread of misinformation that have prompted this qualitative study on quantitative data. Due to the public nature of the discourse focal to the study, the data gathered for analysis is publicly available. The publicly available data accounts not only for the most accurate possible representation of how statistics from scientific research are reproduced in the public sphere, but it is also necessitated by the aims of the current investigation: while an in-depth exploration of individual and organizational sentiments surrounding the discussed issues would be a worthwhile venture, the current research is more concerned with tracing the transmission and representations of the statistics between different spheres of knowledge. For the analysis of how statistics from science research are represented in different knowledge spheres, the data in the current study consists of just that: statistics and their web-based public representations. The present chapter commences with a description of the data for the study and its means of collection, then outlines the crucial features of qualitative research practices that lend themselves to this undertaking.

Gathered during a seven-month period between August 2020 and February 2021, the data is comprised of two main categories. The initial dataset is a collection of statistics from scientific journal articles pertaining to the three publicly debated topics that are rooted in scientific research. Criteria for this initial dataset was based upon 
factors that rendered the statistics from the research articles relevant to the aims of the investigation, meaning they were selected based on their presence in the public sphere. Specific requirements for the selected articles were: (1) that they were published in a peer-reviewed, academic journal; (2) that they must have been published from 2015 onward, as the study seeks to explore the transmission of information as it happens more quickly than it would have before technological advances - in the case of the current study, that means within five years; (3) that their statistical findings are clearly presented; and (4) that they can be connected to topics in their fields that have incited public debate. In addition to the specified criteria for the selected research articles and their included statistical data, the selection was also informed by the social and contextual factors surrounding the research. More specifically, the type of human behaviour that would be suggested to change as a result of the findings played a role in the types of research gathered for the current study. In order to compare several representations of statistics from the academic research sphere in online web-based discussions, the implications of the findings in the analyzed articles influenced the selection decision so that findings which impact human behaviour on a day-to-day basis, in a singular or unusual set of circumstances, and in a long-term sense. For statistics that have a daily impact on human behaviour, the selected research is from the field of Health Sciences; for that which impacts human behaviour and decision making in a specific situation, the selected research is from the Biology and Health Sciences fields and relates to vaccines; and finally, the study prompting long-term behaviour and ideological impacts is from the field of Earth Sciences and relates to climate change. With each of the selected research articles being derived from a different disciplinary field of science, the opportunity is 
available to identify differences between how the recontextualizations of the statistics may vary depending on both the field of science and the supposed impact on human behaviour prompted by the studies' findings.

Analysis of the selected articles could, in itself, account for its own endeavour. There is ample evidence of rhetorical devices and recontextualizations within each article, however the focus of the current study is to identify those features outside the sphere of the academic origins of the studies. With the intentions and scope of this investigation in mind, the relevant features of the research articles are identified and isolated so that they may be consistent with one another, and so that there is a direct and specified approach to the inquiry that involves a diverse collection of data. The first, and perhaps most expected feature to be identified is the presented statistics in each article; this portion is foundational to the current research in that the numerical data representation from the initial articles constitutes what is being traced between the spheres of knowledge.

The second feature of the initial articles to be isolated includes the section of each article that serves to explain the implications of findings. A commonly expected section of any academic research article, the researcher's description of the implications of their findings is a direct means through which they are able to communicate the relevance, consequences, and oftentimes unanswered questions resulting from their studies to their audience. While, in most cases pertaining to discipline-specific science research, the audience of those articles consists mainly of fellow researchers, specialists, academics, and students within the field of research. When this information crosses into the public realm of accessibility, the audience is undeniably more varied in their understanding of 
the research and its context, and largely unfamiliar with the academic discourse from which it derives. With consideration for this discrepancy in understandings, the "implications" sections of the selected articles are analyzed for their complexity, use of specialized language, accessibility, and explicitness. While this portion of the data will not necessarily be focal to the analysis, it provides the opportunity for the public representations of the statistics to be analyzed in contrast to how clear the researcher was in stating the implications of their research; it remains unclear whether there is a connection between explicit, accessible statements of implications and public understanding, but this point of investigation does provide unique insight for the transmission of information between knowledge spheres in this particular context.

Beginning the data selection with seminal research articles from academic science articles was a necessary first step in the current research, but the subsequent dataset is comprised of the public usage of the statistics in question and is significantly larger in size. Another point in the study that highlights the capacity of this type of analysis is the potential to explore a variety of web-based discourses as they exist on different platforms. Not only is there an abundance of material to explore on the various public platforms central to how we engage with information, but it is also seemingly endless. An approach to narrowing the scope of this material for the purposes of a focused analysis was the decision to target a single online platform as opposed to drawing from several.

A (2020) survey-based study that identified which social media platforms were the most popular amongst Americans as sources of news and information determined that Facebook had the highest percentage of users seeking information, followed by YouTube and Twitter. Facebook and YouTube serve as tremendously large and accessible 
platforms for a wide variety of topics and allow for users to experience and utilize several modalities - these elements alongside the massive global populations that use these platforms explain the high percentages found for people who claim to access their news from these sites. It is the wide range of modalities and either unlimited or liberal character limits for commentary and posting on these sites that make them too expansive for the specific data required for the current study.

It is both the parameters for posting, particularly the character limits, along with the knowledge that twitter is more popular amongst its users for news and political discussion than any other topic (Appendix D) that drove the decision to select Twitter as the platform from which the public representations of statistics will be derived. Through the current investigation, it became evident that Twitter was the most accessible platform for the purposes of tracing one post back to its origins when compared to Facebook and YouTube, which is an invaluable advantage for a study that explores transmission of information. While Facebook is conceived of as an inherently social platform and YouTube as one that is mainly used for individual entertainment, Twitter appears to be the most politically and ideologically focused platform in terms of how its users interact with one another. One of Twitter's features that makes it valuable to the current research is the way in which it facilitates conversations between individuals who would perhaps never have the chance to connect under different circumstances. This is especially useful in the case of the current study because it allows for the analysis of the data as it exists within different social boundaries, but on a shared medium. Twitter does have various unique features that distinguish it from other social media platforms, including the ability to view likes, hashtags, and retweets, amongst others. While any one of those features 
could provide a unique area of analysis, this study will not necessarily explore all of them. Due to the purpose of this research, which includes the aim of exploring where the focal statistical data travels online and how it functions, this analysis will consider the retweet function, but not the amount of likes or hashtags. This is not because the hashtags and likes are not valuable tools or areas of investigation, they simply do not contribute to the research aims in the way that exploring the retweet function does.

The tweets selected for the dataset fall into two categories: the primary groups consist of any tweets that directly address the statistics from the three research articles anchoring the data, while the secondary groups include any relevant commentary on the primary tweets. With the inclusion of both categories, the data allows for an investigation of both the specific transmission and representation of the statistics, and brings to light some of the ideologies and conceptions connected to those numerical figures.

To achieve the most thorough and comprehensive data inquiry, the chosen method for analysis is modeled after what Holliday (2015) describes as a classic approach to qualitative data analysis. This four-step process includes: (1) coding the tweets to identify key words and phrases; (2) determining common themes amongst the tweets with the aim of grouping those with common occurrences; (3) constructing arguments based on the themes to determine what can be learned from the data; and (4) going back to the data or refinement which is an ongoing process throughout the analysis that includes reevaluation of codes and themes as the analysis develops.

Following Holliday's (2015) approach to qualitative research and proposed method for analysis is in line with the intention to mitigate the influence of the inevitable subjectivity underpinning most qualitative research. The nature of the study and its 
included data is such that a different perspective or emphasis on different features within the research would result in findings that differ from what the current investigation produces. While there is an underlying influence on what is found simply as a result of the trajectory determined by the line of questioning within this study, the analysis itself is guided not by the aims of the current study, but instead by the characteristics of the data itself:
"Qualitative research looks at instances of behaviour rather than broad tendencies in that it cannot prove, for example, that certain percentages of people believe certain things. An appropriate claim would therefore be that in a particular location at a particular time, certain things seem to be the case. This shows that the purpose of qualitative research is not to prove anything, but to generate ideas which are sufficient to make us think again about what is going on in the world. It is not therefore possible to use qualitative studies to prove or disprove other studies by means of replication. Three different researchers looking at the same set of qualitative data may easily arrive at three very different interpretations, and it may well be the case that the data can only be made sense of by a researcher who has taken part in the total experience of collecting it" (Holliday, 2015, p. 52).

This excerpt from Holliday's discussion of effective qualitative research approaches is connected to his earlier sentiments about transparency in methodology and the importance of a researcher's submission to their data and is also a direct commentary on the crucial aspect of any research - that is to make appropriate claims.

The overall subject matter of the current investigation and the spheres of knowledge in which its selected data operates amounts to a highly complex and multifaceted research endeavour. Although there are hypothetically countless ways in which this analysis could be approached, the explicitly stated categorization of selected data and the justifications for those selections help to bring clarity to a situation that is so obscured by its various involved factors. By narrowing the scope of the research to include data that meets a selected set of criteria and adhering to a set of guidelines that 
have cultivated many accepted studies in the past, the analysis in Chapter 5 seeks to explore the intricate topic at hand in an effective and comprehensive manner. 


\section{Chapter 5: Analysis}

Combining the information set forth from the review of literature with the selected theoretical framework and methodological approach, this chapter consists of the current study's analysis. The analysis will examine the three datasets: health science, climate change, and vaccines - in that order. Each dataset is explored through the lens of a Foucauldian discourse analysis with focus on related social and contextual factors, and are each discussed in direct relation to the research questions guiding the investigation.

\subsection{Analysis: Health Science}

The first area of focus in the analysis is centered on a recent online debate relating to information from the health sciences. The online, public debates surrounding findings from the health sciences are fraught with disagreements and conflicting information as a result of the large amount of diverse information coming from the field's research, alongside the nature of the findings which, for the most part, affect the individual and their daily behaviours. While there is a wide array of specific dietary and lifestyle related findings that derive from research in health science, the study selected as data for the current investigation analyzes the connection between body-mass index and mortality rates. Statistics from a (2016) Harvard study suggest that as body mass index increases, so does the risk of dying prematurely. The research includes data gathered from 4 continents over 5 years and tracks the connections between body-mass index and mortality rates of subjects in various studies from several institutions globally. One specific statistic from the study that made its way to the public sphere on twitter indicates that every 5 units higher BMI above $25 \mathrm{~kg} / \mathrm{m}^{\wedge} 2$ was associated with a $38 \%$ increase for respiratory disease mortality. 
The study's findings made headlines internationally upon its release in 2016 and has maintained notoriety online ever since. Upon searching twitter for an online presence of the study and its statistical data, there was a substantial number of tweets involving the study at the time of the data collection. A significant majority of the tweets depend on a recontextualized version of the statistical findings, in that the tweets relating to the study were all linked to the article from the Harvard Public Health twitter account. While the article linked in the initial tweet from the Harvard Public Health account included the statistical data, they were not present in the text of the tweet itself, which reads: "As overweight and obesity increase, so does risk of dying prematurely". The headline serves not only as a summary of the statistical findings, but also a strongly worded warning that indicates high risk consequences associated with obesity. With Harvard having released the research on twitter with a commentary that encapsulates the findings and their implications, it appears that this packaged form of messaging was compelling enough that a large number of twitter users simply retweeted the initial tweet from the Harvard account without their own added commentary. From a Foucauldian perspective, it is possible that the common social perception of Harvard having an authority of knowledge as an institution contributes to the apparent lack of need for any elaboration on their version of the research findings by the public actors on twitter. This point of analysis speaks to the power of particular institutions and how they serve to structure society, in this case as it relates to the creation and transmission of knowledge.

While the majority of the tweets included in the dataset consist only of the link to the article including the statistics as opposed to providing their own presentation of the numerical findings, there are several instances of twitter users who indicated the statistics 
explicitly in their tweets. A significant feature of this component of the analysis is the discovery that all those (save for one user) who explicitly state the statistics in their original, numerical form are doing so in an argumentative manner and are connected in some way to a dialogue with other twitter users. This observation is indicative of the magnitude of statistical data as an argumentative tool, specifically as it relates to providing proof or evidence for a certain stance taken in debate. Earlier discussions of rhetoric suggest that presentation of perceived 'fact' is a common approach to persuasion in a given argument, and it is apparent thus far that the display of statistics alone can function as a rhetorical device. It must also be considered that the institution from which the findings are produced, along with the vast number of included countries and studies that contribute to the research findings are addressed in the tweets that explicitly indicated the statistics. Though this portion of the analysis does suggest that statistics, on their own, may function as a means of argumentation, their place of origin and the approaches involved with their production are often put forth as further evidence for their validity. Again, at this stage of the investigation this is an observation that relates only to the employment of statistical findings by twitter users as rebuttal in a debate with other users, but it does present yet another instance of the social perceptions surrounding particular institutions and processes denoting knowledge-based authority, and the apparent value of indicating the institutions and empirical processes within one's online argument.

It is apparent that the users presenting the statistics have engaged with the research findings beyond the more easily interpretable version put forth by the Harvard Public Health twitter account, so it should also be recognized that perhaps the 
institutional support for and empirical approach to the research may hold more value to those who are touting these suggestions of knowledge authority than it does to either those on the other side of the argument, or to those who have not engaged with the research in the same way. In any case, an element of the observed arguments between twitter users necessitating analysis is the set of initial tweets that these statistically informed rebuttals are created in response to. This line of inquiry is one that helps to inform a more comprehensive understanding of both the specific features within the analyzed discourse, as well as the broader social context that impacts said discourse causes disputes there within.

One of the more advantageous aspects of the use of twitter for the selected data is the ability it provides to view the connections between tweets in the way of the discussions that occur throughout comment threads as opposed to being bound to the individual postings. Through a search of the discussions that prompted several users to cite statistics as an argumentative tool, the main social issue countering the suggestions of the research was revealed. At the core of each argument that involves the statistics is some type of reference to the body positivity movement or what is commonly referred to online as "fat shaming". The general argument behind this movement is that health is possible at any size and that the widely accepted discrimination against the visibly overweight in society should be combatted. It is not the case that all those who support this movement deny the scientific data, however in the case of the current analysis it appears that the statistics from the Harvard study are used in the arguments made against those who employ the arguments associated with the movement. 
It is through the analysis of the related social argument connected to the research findings that we are able to perceive the degree to which the nature of the online discussion impacts the discourse overall. While in both the post from the Harvard Public Health account and the original research article there is no mention of social conceptions of and attitudes toward obesity, it is evident that those concerns make up a significant portion of the conversation as it exists in the online public sphere. This point of analysis suggests that it is the medium of social media, that being twitter in this particular case, which facilitates the combining of scientific and social arguments as they relate to a given set of research findings. As the statistics are concerned in the context of this social debate, the only places in which the explicit reference to them with use of the actual numbers can be found are in the responses to the socially concerned posts, and that those original posts to which the rebuttals are in response only vaguely address the messaging from the research, but do not include any reference to the numerical data. The data also shows that there are no instances of a twitter user who posted the initial tweet in opposition to the research findings who responded in the thread once the statistics or summary of research findings were put forth in response to their commentary.

It can be argued that the lack of statistical representation in the posts focused on the opposing social argument is the result of those arguments not placing attention on scientific evidence in general, and instead placing all concern on the social implications of the findings as opposed to the physical consequences. It is in the lack of response to any of the rebuttal posts featuring the findings, though, that the durability of statistics within this social argument is suggested. Reconsidering the Foucauldian lens, it should be acknowledged that the arguments supporting the statistical findings are supported by 
institutional backing and time-honoured research processes that contribute to their validity in an argumentative context, whereas the socially driven opposing argument does share the same type of access to evidence, considered to be of equal validity, in support of their stance.

Aside from the social argumentation for which the statistics are operationalized, the selected data includes several instances of political argumentation on behalf of various twitter users. Each tweet in connection with the research findings that constitute a political statement are in relation to either President Trump or the issues with the American healthcare system. While none of the tweets directly address the findings as they relate to President Trump personally, one tweet employs the research findings as a counter argument in a discussion surrounding some of his administration's response to the Covid-19 pandemic, suggesting that the correlation between mortality rates and obesity should also be considered in the context of that issue. The tweet in question stands out as significant both because it exemplifies the usage of the research findings as an argumentative tool in a debate external to the previously discussed dominant, opposing social issue, and also because it was used nearly 4 years after the research was published; this particular instance speaks to both the adaptability of the findings based on the intended argument, as well as the lasting power of those findings in a discoursal context. As it relates to the current area of analysis, being health science data, it does not appear that there is a connection between the social and political contexts in which the statistics are employed, although they are used separately in both socially and politically driven arguments for differing purposes. 
A central point of investigation prompted by the previous review of approaches in rhetorical analysis is the role of the audience in terms of how the focal information is presented. Although we can only make assumptions about who the included tweets are intended for, if anyone, describing the available information about the authors of the posts who account for the dataset will help to suggest who their audience may be. A vast majority of the tweets are put forth by public actors who do not specify any title in their name, but there are three sets of identifiable social roles included in the data: (1) widely recognized health organizations; (2) doctors or twitter users who included their titles in their twitter names; and (3) public actors. There are several instances in which users have added health and wellness related hashtags to their posts including the posts that appear to indicate support for the research findings in a way that aligns with either their businesses or personal beliefs - for example: "As obesity and overweight increase, so does risk of dying prematurely \#trainhard". Some doctors, or at least users who have 'MD' in their twitter handle, who retweeted the research would use the pronoun 'we' when discussing what they know about the findings as an apparent means of aligning themselves with the science community. Several health-related organizations shared the findings, including groups focused on nutrition, cardiovascular health, and holistic healing, and in most of these cases the findings are shared in the form of a retweet without any extra commentary. The public actors presented various forms of commentary in relation to the research findings, with the majority of them retweeting the same post from the Harvard Public Health account. The public actors account for the identifiable group most commonly to add their own commentary to the retweet, or to engage with other users in debate with use of the original statistics. In summary, there is no significant 
connection between the type of tweet posted and the evident social role of those who posted, except for the fact that public actors are the only posters who appear to engage in online debate with other users.

As a final point investigation in this first segment of the broader analysis, the focus is shifted to the original presentation of the statistical data as it was published in a science journal, not the recontextualized version provided by the Harvard Public Health account. The value of this specific focus lies within opportunity to consider how accessible that original representation is to those without a science background, as compared to that which is presented by the Harvard Public Health account and the information that has spread on twitter. The original article presents the numerical findings in a highly complex manner that poses potential difficulties in understanding by those without a background in science. Although the findings are presented in full sentences, there are almost more numbers and symbols than there are words, which is common in scientific reports of findings but nonetheless complicated from the perspective of the average person with no specialized science knowledge.

Immediately following the presentation of statistical findings is a section titled "Interpretation", which consists of two sentences that essentially translate the statistics into a more comprehensible communication of meaning. The 'Interpretation' reads: "The associations of both overweight and obesity with higher all-cause mortality were broadly consistent in four continents. This finding supports strategies to combat the entire spectrum of excess adiposity in many populations" (Di Angelantonio et al, 2016, p.776). The presentation of findings, and the interpretation more specifically, is a worthy point of analysis in relation to the overall aims of the study because it is evident that there are 
distinct commonalities between the interpretation within the journal article and the message shared on twitter by Harvard Public Health. More specifically, it appears that the most common message associated with the statistics on twitter is in line with what is suggested by the interpretation in the academic literature. This factor could possibly be the result of the clarity in the messaging found in the interpretation section, but it is also likely that its reproduction through the Harvard Public Health account was integral to how the information spread because of the notoriety of the institution and its related public trust.

Two main features that characterize this initial portion of the analysis are: (1) that the presence of the social argument in opposition to what is suggested by the statistics influences the role of the statistics in the discourse - in this case, they became a rhetorical, argumentative tool; and (2) that the interpretation of the statistics intended for public consumption is far more commonly posted than the numbers themselves.

\subsection{Analysis: Climate Change}

The second dataset for analysis focuses on the risks associated with climate change, specifically as they relate to fossil fuels. Similar to the previously explored research findings from health science, the current findings in question are the result of a collaborative research endeavour that combines data from various studies within the field of environmental science, all with the aim of determining the consequences of fossil fuel production on a global scale. The research is driven by the United Nations Environment Programme and the Stockholm Environment Institute, who produced a comprehensive report on the risks associated with fossil fuel production titled "The Production Gap", which includes the findings from several scientific studies. The statistic from the report 
that spread virally on twitter warns that "to follow a $1.5^{\circ} \mathrm{C}$-consistent pathway, the world will need to decrease fossil fuel production by roughly $6 \%$ per year between 2020 and 2030". This finding was put forth by the United Nations Environment Programme twitter account with a link to the full report and the following text: "governments must wind down fossil fuel production by $6 \%$ per year to limit catastrophic global warming". The tweet has generated a diverse range of responses in the public sphere on twitter, which account for the data under examination in this segment of the analysis.

With contextual focus it is apparent that the organization responsible for both the tweet and the research, the United Nations Environment Programme, bears its own implications for how the data is accepted in the public sphere. On one hand, the official nature of the organization suggests that they serve as a reliable source for information, but on the other, their status as a widely recognized, global organization poses the chance of pre-existing attitudes towards them that could negatively impact how the presented research is perceived. The Foucauldian lens brought into focus the apparent level of knowledge authority held by Harvard in the previous portion of the analysis, but in this case, it should be considered that the organization currently in question is more widely known for its social and political authority than it is for knowledge production. With social and political elements being fundamental to the United Nations, its role in society makes it more susceptible to being viewed in a polarized manner, depending on their stance when it comes to controversial issues. While this feature of the data is not directly connected to the science data, it is an essential starting point for the exploration contextual factors that may have an impact on how the discourse functions. Furthermore, it is imperative that the organizations and institutions guiding the three sets of statistics 
focal to this study be explored for their differing social roles and perceptions, as to avoid suggesting that they all function the same way as power structures; because they are varied, so too is their influence on the discourses to which they are connected.

The first identifiable theme in the data is found in the conversations between twitter users in the comment section of the tweet from the United Nations Environmental Programme account; in response to the aforementioned warning tweet suggesting that governments must wind down fossil fuel production, several users engaged in a discussion that appears to be a solution focused reaction to the message. In their discussion, the users vouch for three different varieties of reactors as proposed solutions, even comparing them to wind and solar technologies. Other users connect the issue to hybrid and electric vehicles, suggesting that "clean air vehicles are the future". Another instance of solution focused messaging throughout the data includes several users theorizing about how the issue could be addressed, with one stating that production could be dealt with simply by lessening use, and another user more specifically stating the same sentiment by proposing that shared travel should be encouraged through policies and promotions from places that commonly prompt travel, including workplaces and educational institutions. This theme provides an example for how the conversations between users in response to a presentation of research findings in the public sphere can be collaborative and is does not always consist of the type of argumentative debate analyzed in the previous set of data. The seemingly more positive type of conversations witnessed within the current data could be the result of the users having the common goal of offering effective solutions, but it could also be the case that they are on the same side of the social debate that exists in relation to climate change. 
In the case of the ongoing public debates around climate change, there are various commonly taken positions regarding perceptions of the related research and its suggested implications, with skepticism being an evidently popular stance. Amongst the discussed tweets which demonstrate a set of cooperative conversations in line with the suggestions of the focal research findings, are several posts from social actors who explicitly state their skepticism of climate change and vehemently deny the findings. The first tweet indicating denial reads: "There is no such thing as global warming or climate change, you fools! The seas are not going to rise!" In the same thread as that tweet, other users demonstrate a similar mentality, writing that: "I don't believe anything and I'm tired of you people - you can't control my mind" while another states: "Quit telling us what to do." It is at this stage that the social argument opposing the presented statistics is made clear, and that it is not just the case that the implications of the science are denied, but also that those in opposition to the science display significant concern for their freedoms, as evidenced in the last two posts.

As for the examination of the tweets that are grouped as being in opposition to the science, it is necessary that their differences be considered so that features of this grouping are not assumed to be entirely consistent, as the data does demonstrate a key difference within the category. Although it is likely that there is a broader shared ideology between those who explicitly deny the science and those who voice concerns about the possibility of being controlled, it is critical to note that these are two separate arguments. The denialist tweet that suggests there is no such thing as climate change is representative of those who deny the scientific research findings, whereas the tweets concerning power and control are rooted entirely in the social and political aspects of the 
debate. It could be true that a climate denialist who is focused on their lack of belief in the research findings has no concern for the social consequences, and it could also be true that those focused on the social consequences have no regard for the scientific data. One commonality of the tweets that indicate opposition to the findings, though, is that the statistics themselves are not present in any, and that much like the health science data, the numerical figures are only present in the posts that appear to be in support of the research findings.

Shifting the focus to the evidence of how information is politicized within the online debate surrounding climate change, the data presents several instances of reference to political aspects within the discourse. The nature of the climate change debate is such that the suggested need for action from individuals and governments alike often produces controversy regarding how the issues should be addressed and who is responsible. Ultimately, these questions lead to implications that are inseparably political, providing a worthwhile place of investigation for how the statistical data functions in that specific realm, from a discourse perspective. Analyzing this broader discoursal feature in the context of the data at hand, it is apparent that aspects of the messaging from the United Nations Environmental Programme account is inherently political, in that they involve the topic of government response within their presentation of the research findings. Instances of public responses that indicate the presence of a politicized perspective of the debate exist in the data on both the sides of those who appear to accept the scientific data and those who are opposed to it. In the conversation that addresses potential solutions to combat fossil fuel production, one user puts forth that they would like to see their country "take the lead" on the proposed solutions, while various other users in support of the 
statistical findings have included in their post the original commentary that governments must act. The only example of a direct connection between a sentiment and a specific political figure can be found in the post from a user in opposition to the findings, who states: "Quit telling us what to do." and has a photo of President Trump as his account profile photo. Evidently, there are no posts from those in opposition to the statistical findings that include the original messaging in the commentary, providing another example of how the explicit inclusion of the numerical data and its suggested implications are seemingly only present in the posts supporting the research, and not in those contrary to it.

A good portion of the data is comprised of the commentary from public actors who do not indicate any specific organizational affiliation, but there are several cases of the research findings having been shared through organizational accounts, or where the user's handle indicates their occupation or affiliation. To name a few, a trade union organizational account, a microbiologist, and a member of European Parliament all posted the research findings through their verified twitter accounts, while other social commentators with significant followings also shared the findings. Upon closer inspection of all posts, including those which appear to be in opposition to the findings, it can be seen that only those who demonstrate support for or cooperation with the findings have any notoriety or identifiable affiliations, and that it is only public actors who pose themselves against the research and its suggestions.

The examination of the apparent social roles of those who have engaged with this segment of the current study's data reveals that there is an apparent theme amongst organizations and public figures involved with the discourse, in that they produce similar 
commentary that is directly in line with the knowledge put forth in the research. In fact, many of these posts include the exact messaging and link from the original United Nations Environmental Programme account post. In a few cases, the findings are elaborated upon by the users, but in most it appears that the original message is simply being reiterated. The repurposing of original messaging can be analyzed for its social context in a few ways: as a rhetorical tool, it is an apparent attempt at adding validity to one's personal argument by referencing knowledge that has institutional backing. As a social act, it can also be seen as a means of individuals and organizations aligning themselves with a broader ideology that the research findings indicate - one that places emphasis on the validity of the research and the necessity of action-based responses to mitigate the risks associated with climate change. From this angle, it is apparent that the statistics in the current segment of analysis are directly connected to social structures that possess some degree of social and political power, and again that those in opposition to the suggestions of the research findings do not have access to the same type of ideological structure, at least in this particular example of the discourse.

As done in the analysis of the health science statistics, the presentation of statistics from the original published studies must be compared with their recontextualizations on twitter for the purposes of identifying any differences between how the numbers function in different areas of the discourse. As previously mentioned, the statistics that are presented by the United Nations Environmental Programme account, as derived from the Production Gap report, are a recontextualization of the findings from several environmental science research studies that contain a vast amount of numerical data that contribute to the numbers indicating specifically how much fossil fuel 
production must decrease and in what timeframe that decrease is proposed to occur. In comparison to the Production Gap report, the original studies are difficult to come by and, as with many peer-reviewed studies, are largely inaccessible to the public as they require affiliation with an educational institution or have a cost associated with access granting. Since the studies which contributed to the findings put forth by the United Nations Environmental Programme exist in different research articles, there are a few representations to consider. What the original representations have in common with one another is similar to what has been demonstrated with the health science data, in that the focus of the findings sections in the research article emphasize the numbers as opposed to their implications and are presented in a technical manner that is not easily comprehensible to those outside the specific field of science.

The recontextualization of original statistics, in this case, appears to have been an effective means of producing easily transmissible knowledge that focuses on statistical data but in a way that contains both the implications of the findings and a suggested proposition to incite action-based responses. This recontextualization also includes a reference to where responsibility lies in terms of implementing responses to the discussed risks, in that the world's governments are named within presentation of the findings. This is a crucial point of consideration in a discourse that involves the ongoing debate around climate change, because of the fact that much of the controversy surrounding the topic derives from disagreements over who is responsible for solving the issues at hand and how the solutions and/or consequences would affect human behaviour. Not only does the recontextualization effectively make the research statistics more apt for public consumption, it does so while ensuring that its real world implications are made clear. 
Representative features of the current section of analysis include both social and technical aspects of the discourse in question. From a social perspective, it appears that the level of organizational support for the statistical representation has had a significant impact on how the discourse functions in the public sphere, specifically for how it brings together various types of public figures by means of them aligning themselves with the research findings and its connected implications. From a more technical outlook, it has been shown once again that presence of the numerical data exists only in the posts that appear to be in support of the findings, and not in those that are in opposition to it.

\subsection{Analysis: Vaccines}

The third and final area of focus in the current study's analysis pertains to one of the most widely recognized public debates involving scientific research: vaccines. Although the Covid-19 pandemic has brought the vaccine controversy into the spotlight throughout the past year, it is important to consider that there has been a pre-existing debate surrounding vaccines for several years leading up to the currently occurring discourse. While there is a wide variety of statistical data relating to vaccine research that would be suitable for the current portion of the analysis, the selected research is unique in that it captures what was transpiring in the online public discourse in real time when the findings were released during the period of data collection for the current research endeavour. The statistic focal to the final portion of the analysis was released on twitter by the Oxford Vaccine Group official twitter account in early February of 2021, when research had determined the efficacy of the first dose of the Oxford vaccine, now more commonly known as AstraZeneca. The tweet published by the official account reads: "A new study shows that our \#OxfordVaccine offers protection of $76 \%$ up to 12 weeks after 
a single dose, with further data supporting a 4-12 week dosing interval". At the time that the findings were released, the controversies around this particular vaccine and the instances of blood clotting had not yet come about, and the Oxford vaccine had, up until that point, seemed to be the most promising potential defence against Covid-19. Even at this stage, when encouraging data was being released in a highly anticipated context, there was still a diverse range of public responses generated by the release of the statistical data on twitter.

The first and most clearly identifiable theme in this third set of data that distinguishes it from the previous two is the frequency of comments that are either celebratory or congratulative in the twitter posts made by public actors and known public figures alike. In the context of the discourse and its broader social implications in the timeframe that it was analyzed, this type of commentary exhibits how dire the need was for an effective vaccine. It also serves as an indication of how engaged members of the public were with the scientific data, in that there was a level of anticipation from public actors on a global scale that preceded the presentation of the statistics at hand. While, in any other context, the presentation of this type of data may not have elicited such a positive response from members of the public as there is no particular phrasing in the messaging that suggests the findings represent an achievement or cause for celebration. But, due to the globally shared experience that has been the Covid-19 pandemic, we can consider this aspect of the discourse as exemplifying the way that science research does not exist in isolation, but instead that it is intrinsically connected to real world issues that have a heightened level of anticipation when there are high risk consequences involved. 
Upon consideration for the positive responses to the online presentation of statistics, the contrary sentiments that are ever present in this example of the discourse are an essential point of investigation. The opposing arguments to the statistical data that have come about in the previous two sections of the analysis have been rooted in social and ideological beliefs, and have presented themselves in the twitter threads as either argumentative or defensive commentary. It is in the commentary that opposes the statistics relating to the Oxford vaccine, though, that present the most explicit forms of data rejection and the most deliberately emotive language thus far in the study overall. Terms that arise in the investigation of data opposing commentary include: "stupidly naïve", and: "what a load of shit", amongst others. The strong language and clear opposition to the represented statistics, and vaccine use more broadly, is representative of an ideology that is connected to several social phenomena that include a denial of the virus as a whole, a distrust in public health and government institutions, an opposition to vaccines, and a rejection of freedoms being encroached upon, to name a few. While it cannot be deduced that any of the twitter commentary opposing the statistical data in this specific example of the discourse can be connected to any of the mentioned ideological stances, it is important to note that scientific data rejection in this case can be connected to any number of those beliefs, whereas the previously explored discourses present opposing arguments that are somewhat easier to define in terms of their reasoning. This aspect of the current discourse of examination is yet another way in which the statistics function differently than they have in the context of other scientific research and their related social implications. 
Another unique feature of the current set of data in question as compared to the previous two is that there is not only the existence of those who appear to support the statistical findings and those who oppose it, but there is ample evidence of a third group that whose commentary is more inquisitive than it is indicative of any stance on the research findings. Some of these posts include commentary such as: "Is it a similar protection \% to the South African variant?"; and "I'm concerned that while the Oxford vaccine has some protection it's not as good as Pfizer for people over $65 . . . ”$ Commentary categorized into this 'inquisitive' group operates a few different ways in the discourse, as it functions as a line of questioning seemingly directed at the Oxford Vaccine Group in some cases, while in others it appears to be intended to prompt a conversation with other twitter users. With these different functions in mind, the question of audience as it relates to rhetorical purpose within the discourse comes into focus once again. The inquisitive commentary, as it functions on twitter specifically, demonstrates the ability to reach a wide range of public actors through use of the platform and suggests that these types of commentary are intended for all audiences since there is no real evidence of any explicitly stated sentiments or ideological affiliation.

The current set of data provides another distinctive feature in relation to those previously explored, in that there is evidence of users who appear to be experts engaging with the conversation by furthering the data with their own explanations. In one case, a user whose handle indicates that they are a doctor shares an infographic explaining how the vaccine was made and how it works. In another case, a user engages in conversation with one of the commenters who questioned the safety and efficacy of the vaccine by providing them with links to official government health information accounts. The 
engagement of these users points to a willingness to cooperate with others in the online discussion in order to spread what they deem valid information for the purposes of educating. Analysis of this discoursal feature sheds light on the fact that the presentation of statistics by the Oxford Vaccine Group on twitter is not a recontextualized form of the research findings, and that there are several users in the conversation who are doing the work of recontextualizing the statistics by expanding upon the provided information and making reference to its real-world implications.

Viewing the data with an emphasis on its political contexts, there are various instances that explicitly implicate political figures and nation specific aspects of the discourse. UK prime minister Boris Johnson shared the study's findings through his official government account and presented them with a message that includes a figure of how many people in the UK had received their first dose at the time. The prime minister's representation of the study's findings exhibits another means through which statistics can be operationalized as a rhetorical tool in that his framing relays an essence of pride and accomplishment, and acts a means of him taking credit for what he calls "fantastic" for supposed political gain. Another point at which the prime minister is referred to in the twitter discussion can be found in a post from a public actor who makes a complaint about the exact issue that Johnson had been celebrating as an accomplishment: “ $\ldots$ when will Johnson ditch his ego driven target and start a MASS $2^{\text {nd }}$ dose programme?". The conflicting tweets over the topic of vaccination rates is somewhat disconnected from the originally presented statistical data, which serves as a discoursal feature demonstrating how the topic of discussion can stray when that data is 
not presented with explicit reference to context, and also illustrates how socially and politically embedded the statistics are in this case.

Beyond the more clearly identifiable examples of connections to political context within this online discourse are the underpinning power structures that we have been contemplating with a Foucauldian perspective throughout the analyses in the current study. In terms of the selected data for the discourse of vaccines and its included statistics, the institutions and organizations supporting the vaccine data are, yet again, a necessary point of consideration. This point is especially pertinent in the case of the accelerated studies that led to this early vaccine, because a large portion of the global population was of the mind that governments and vaccine manufacturers had ulterior motives when attempting to produce the vaccine in a short span of time. This distrust for the institutions connected to vaccine research, production, and distribution is evidenced by the majority of the commentary that questions or rejects the statistics as they are presented by the Oxford Vaccine Group twitter account. This is a critical area of focus in the overall investigation, as it helps to inform an understanding of the potential reasoning behind the 'anti-vax' mentality and the denial of Covid-19 more broadly. It is also a feature of the research that points to the value in a discourse analysis that is explored for its contextual elements, particularly one that places emphasis on seeking to explain how the external factors influence how the discourse functions and what that means in terms of practical consequences. When it comes to the consequences resulting from a prevalent opposition to the Covid-19 vaccines, there are direct implications for everyone in terms of how the virus spreads and the regulations put in place in response to high numbers of 
transmission. This is perhaps a contributing factor for why there is such a high degree of engagement from the public on twitter in relation to this specific issue.

A feature of the broader context that further complicates the topic at hand is the current public beliefs about the AstraZeneca vaccine. With a few reports of dangerous side effects including blood clots resulting from the vaccine, fear was sparked in the public to the degree that many countries have now chosen to not administer that particular variety of vaccine. Despite claims that the vaccine is safe and effective from science researchers and health professionals alike, the vaccine's rejection by a large portion of the general public remains. One of the dangers associated with this situation from a discoursal perspective is that we have evidence of skepticism and rejection of the vaccine before its few instances of negative results had gained such a significant amount of attention in the public sphere. With that, it can be presumed that those who were previously skeptical viewed these instances as evidence for their pre-existing beliefs about the vaccine. Moreover, there are rarely any cases in which anecdotal evidence relating to beliefs that oppose science research have such extreme and evident repercussions, which is a factor that furthers the illusion that there is scientific evidence to support the anti-vaxxers' claims.

A critical feature of the analyses thus far has been the identification and exploration of who is engaging with the statistics on twitter and how they either employ or avoid the statistical data in their online commentary. As previously mentioned, the presentation of the Oxford vaccine (AstraZeneca) statistics on twitter generated responses from a variety of public actors, public figures, politicians, doctors, and other science experts. Consistent with the findings from the previous two analyses in the current study, 
there is no evidence of the statistics being used in the commentaries by those who appear to be in opposition of what the research suggests. It is also a shared characteristic with the preceding analyses that any organization or user who identifies themselves for their public role or science background appears to be in support of the research findings, and are either trying to spread the information or are engaged in a conversation with a user who presents opposing sentiments.

Finally, the current analysis shifts focus to explore the original representation of the statistical findings for a comparison with how they are presented in the public sphere on twitter. Another way in which this dataset is unique from the previous two is that the research findings changed so quickly that the study from which the statistics in question derive is no longer publicly available online. Updated versions of the research behind the AstraZeneca vaccine do place most emphasis on the numbers and what percentages of protection are expected as opposed to including interpretations or written explanations. It should be noted that this factor is very likely a result of the need for the numerical data in the shortest time frame possible, based on the needs elicited by the pandemic. It is also important to reconsider here that the accessibility of information on twitter created the opportunity for the recontextualization of the statistics to occur within the conversations held on that platform, since they were not presented with any explicit mention of context or implications.

It is clear that there are several elements of the vaccine-focused set of data that differ from the first two in the current study. Features that characterize this portion of the analysis include: (1) the presence of many celebratory messages as prompted by the high level of anticipation for the release of this data; (2) clearly identifiable ideological 
representation connected to the anti-vax population; (3) the presence of a third group who brought inquisition into the online dialogue; and (4) recontextualizations of the statistics that occurred within the twitter commentary as opposed to the original message put forth but the Oxford Vaccine Group. At this stage, there is ample knowledge gathered from the preceding three analyses that provides us the opportunity to compare and contrast the features from each discourse situation, for the purposes of discovering how, if at all, the facilitation of transmitting accurate scientific data online in the public sphere may be possible. 


\section{Chapter 6: Discussion of Analysis}

Following the broadly diverse analysis accounting for the most significant portion this study is the opportunity to contemplate the various identified features of the discourses for how they contribute to the overall aims of the current research. Recalling the originally stated purpose of this endeavour, the intention has been to explore how science statistics can be presented in online public debates in a way that facilitates the effective transmission of knowledge from the science community into the public sphere. The analysis has shown ample evidence for the different ways that science statistics function in the public sphere on twitter, based on the various fields of science they derive from and the many contextual factors that impact them. This discussion of findings seeks to contemplate what has been indicated by the three-part analysis, as it relates to the research questions guiding the current study. One fundamental feature of the approach taken for this study is the capacity for comparison between different fields of science and the different contexts there within; therefore, the purpose of the following discussion is to explore those comparisons within the deliberations for each of the leading questions. The coming discussion explores four distinct themes made apparent by the analysis, including the function of statistics in public arguments, the ideological factors that impact surrounding social contexts, the rhetorical capacity of the explored statistics within each debate, and finally, the differences in representation of statistics between the originally published academic work and their representation in the public sphere.

Before arriving at any conclusions about the many factors surrounding the statistics and how the discourses are impacted, the overarching question of how presentations of statistics in public online debates operate must be considered in 
connection to the analysis. One of the more discernable features of how the statistics function across each of the separate explored online discourses is that each time the statistics are presented by a twitter user (not including the original poster) in their numerical form, they are being used in support of or cooperation for what is suggested by the research findings. There are cases in each of the discourses of opposition to what is suggested by the research findings, but never in those commentaries do the statistics appear in their numerical form. When the statistics are repurposed by twitter users, it is most often done in response to other users with whom they are engaged in a debate of opposing sentiments regarding the presented research, which is, again, the case for each of the explored discourses. It is not just the lack of the numerical representations within commentaries in apparent opposition to the science that points to the rhetorical power of statistical data, though, as the health science analysis shows that each time the statistics are referenced in an argument, there is no response from the opposing twitter user. In both the climate change and vaccine analyses there are responses to the statistical references within debates, yet they make no reference to the science and only to the connected social, political, or ideological argument.

Another way this finding can be considered is that there appears to be more of an opportunity for twitter users who are opposed to the science data to respond with a contrary social debate when the statistics are not present, and also that in these instances it is seemingly easier for them to ignore the statistics and refer to other forms of supposed evidence. This is demonstrated in the one of the climate change debates when a user suggests that "the seas are not rising", and in one of the vaccine debates when a user "dares" another user to research death rates as a means of suggesting that the vaccine is 
not necessary. At this stage, the findings suggest that scientific statistics function as an effective argumentative tool in online public debates, and that they have the potential to prevent sentiments that oppose the science from being as prevalent, as evidenced by the many science-opposing sentiments that appear where there is an absence of numerical representation.

While the use of statistics as a rhetorical tool is the most obvious commonality across all the explored discourses, another function they serve is to prompt elaboration by those who support the findings or who have an apparent knowledge of their implications. This function is evidenced several times throughout all three sets of discoursal data and is especially prominent in the case of the vaccine discourse, in which there are multiple instances of doctors and science professionals expanding on the knowledge that is put forth in the original tweet. It is shown that the statistics, at least in their numerical representation, are used more in response to an argument or in debate as opposed to being used in individual commentary, which generally includes more text language and, in some cases, even infographics to describe the findings. That said, the role of the statistics from this perspective can be seen as organizing their related conversations as they are occurring on twitter, and in such operate to create an online space in which anyone who is engaged with the issue can connect, regardless of their physical location or social role.

As a final point of significance pertaining to the first research question of how the statistics function in the analyzed discourses, I wish to recall the findings from Hajer (2005) outlined previously in the literature review which suggest that discourse coalitions of opposing ideologies could be seen to use similar argumentative strategies when engaged in online debates. Based on the analysis within the current research, it appears 
that in the case of the explored discourses that account for this study's data, that this finding may not apply to the use of statistical data, in that those who oppose the findings in question do not present other statistics, and instead that they avoid them altogether.

Having addressed the main findings connected to the technical function of the statistics within the online discourses, the focus now shifts to consider more of the factors that impact the discourses in question. The second research question seeks to uncover what evident ideologies opposing the statistics are present and how they affect the discourses. This line of inquiry is one that demonstrates the variance between the three sets of collected discourses, and in that confirms the benefit of having taken a comparative approach to this study. Each set of statistics from scientific research and their observed online discourses have at least one identifiable ideologically driven argument that appears at some place in the twitter discussion, be it in response to the original post or in debate with other twitter users. What is significant about the findings relating to these opposing arguments is that they can all be traced to a rejection of proposed changes to human behaviour, regardless of the fact that these arguments have nothing to do with one another between the three explored discourses. As it pertains to the arguments opposing vaccines and those opposing the data concerning obesity, the proposed impacts suggested by the science findings would have direct impact on an individual level, be it through the implementation of lifestyle changes or by receiving a vaccine. When it comes to the proposed impacts suggested by the climate change data, the users in opposition to the findings assume the stance of being individually impacted even though the findings are presented with explicit mention of governments and their responsibility to limit fossil fuel production. What can be gathered from this set of 
findings is that we have evidence of those whose beliefs involving the rejection of scientific knowledge are not persuaded to change those beliefs even when confronted with accessibly presented statistical data.

There is value, at this stage, in exploring the nature of the opposing beliefs and ideologies that have presented themselves within each analyzed discourse. The commentary in opposition to the findings of the health science statistics is directly connected to beliefs that are inherently social in nature. The opposing commentary in this case does not include any explicit rejection of the statistical data, rather there is an apparent prioritization of the social repercussions connected to the spread of the science knowledge at hand. This case proves disparate from the opposing sentiments evidenced in the other two discourses in that there is no explicitly stated lack of belief in the statistical data, instead there is only a disregard for it.

In the opposing commentary that exists in relation to the climate change and vaccine statistics, there is ample evidence of the explicit rejection of their validity within both discourses. These two cases also differ from the discourse of health science in the current study, in that they present stronger connections to political arguments than what is seen in the responses to the Harvard research. While we cannot connect all the arguments directly to a specific political stance, each set of explored statistics has prompted at least some political reference. This in mind, we can infer that scientific knowledge is being politicized even in the presence of clearly stated statistical data. Considering the analysis as a whole, it is apparent that the political polarization of science does occur, but not in a way that applies to all science. Instead, it seems that individuals operate on a selective basis when it comes to which science they choose to believe, in conjunction with how the 
related opposing arguments affect them and their ideological beliefs or political affiliations.

It should be noted here that socially informed argumentation around scientific knowledge should be expected with regard for the purpose of scientific research, that it serves to find solutions for issues that exist in the real world. More plainly, this is to say that science does not exist in isolation, and that it is very much informed and impacted by the contexts in which it exists. This too can be said for the conversations that surround it, particularly the ones explored in the current research, which suggests that in an attempt to determine how to effectively transmit data from the sciences into the public sphere, the significance of the contextual factors surrounding the discourses should be emphasized.

The discussion of contextual factors that are inherent to science data and its transmission provides a suitable juncture to consider the third research question guiding the study, that seeks to explore the differences in how the statistics are presented and accepted within each of the examined discourses. The current perspective demonstrates another way in which the inclusion of the discourses relating to three different sets of scientific statistics is beneficial, in that the examination of the strategies used in each allows for the discernability of what is effective in terms of knowledge transmission, and alternately what may be a hindrance. Beginning with what appears to have been the most effective strategy for the transmission of accurate statistical data, the approach taken by the United Nations Environmental Programme and the Production Gap Report serves as an exemplary means of statistical representation in the public sphere. The messaging from the official account recontextualizes the statistics by clearly stating the consequences of the findings in written text along with the numerical representation of 
the data. Also included is reference to a proposed solution which implicates governments as being responsible to enact change, which is a critical feature in a discourse that is fraught by arguments over who should be held responsible for attempting to solve the issues at hand. While there is still evidence of science denialists and skeptics in the examined discourse, overall, the explored discourse portrays the accurate transmission of knowledge that engages a variety of science experts as well as those without an apparent science background.

The consideration for the positive features of the climate change data points to some of the flaws in the representation of statistics from the health sciences. Not only does Harvard Public Health present the research findings by stating the interpretation of the statistical data without using a numerical representation, but they also present the findings in a way that is somewhat sensationalized. While this approach is effective in facilitating the information to gain traction on twitter, the threatening tone of the messaging prompted resistance from many twitter users concerned with the social implications of the research as it relates to overweight populations. In comparison to the effective messaging of the climate change data, it is also worth noting that there are no examples of proposed solutions in the health science discourse as there is in the other examined discourses. More specifically, there was a missed opportunity for both the official account and all those engaged with the discourse to put forth resources that would assist individuals in improving their diet, exercise regime, and lifestyle, but instead the resulting conversations are evidently non-productive and argumentative in nature.

Finally, in the case of the twitter discourse surrounding the selected vaccine data, the representation of statistics is clear, concise, and direct. The numerical representation 
of the statistics alongside plain language renders it seemingly difficult to be misinterpreted. The issues that arise upon investigation of the connected discourse, though, exist within the conversations focused on the socially and politically ideological arguments that occur in opposition to vaccines and the pandemic more broadly, and are not indicative of a misinterpretation of the statistical data. As mentioned in the analysis, unique challenges were present with the vaccine discourse at the time of the data collection because of the urgency with which the statistics needed to be presented to the public. Yet still, the lack of contextual information about the vaccine and how it could impact transmission rates, or even the consequences associated with low vaccination rates within the original presentation of the statistics is connected to a discourse that is evidently replete with misinformation.

The preceding comparisons indicate some of the visibly effective strategies for accurately transmitting science data from its fields of origin into the public sphere, but the approaches that enable negative discoursal outcomes demonstrate how the use of statistics in these discourses can be a powerful argumentative tool, but not necessarily when presented in isolation. This is a major point of significance in the current discussion of findings, because it points to the necessity for science research to be contextually informed at every stage in order to have its intended influence.

In response to the fourth and final research question, the findings were somewhat similar across all three explored discourses in that the original representation of the statistical data as it exists in academic journals is not easily comprehensible for those without a background in the given science. This does not appear to have resulted in any significant confusion once the information reached the public sphere on twitter, due to the 
fact that it had been interpreted and recontextualized by other experts. This finding speaks to the importance of having what we can consider to be "science translators" much like the organizations associated with the Production Gap Report, or the communicators from Harvard Public Health. Unfortunately, it is not always the case that there will be the opportunity for the research to be interpreted before it reaches the public sphere, as seen in the discourse surrounding the vaccine statistics. This in mind, because of the increased accessibility of information online in the public sphere there is a growing level of responsibility for science researchers to be more explicit about the implications of their findings in their published work.

It is in the last point that the most significant implications for future research in discourse studies, as implied by this research, can be considered. Working with the assumption that scientific research practices and the resulting presentation of findings from those fields will persist in a way that is largely unchanging, the opportunity to facilitate the effective transmission between science communities and the public can be occupied by researchers in discourse studies who seek to explore possible approaches to bridging the gaps in understanding between the various spheres of knowledge. This study has shown that there are multiple areas in which misinterpretations are produced and reproduced, pointing to a meaningful opportunity for seeking out approaches that could promote the transmission of accurate knowledge in a way that is contextually informed. This opportunity exists both in in the investigation of writing strategies for academic science literature, and in the exploration of web-based discourses where information is spread. 
Considering again the purpose of the current research endeavour, the fundamental aim has been to explore how specialized information from the science fields can be effectively transmitted into the public sphere to mitigate the spread of misinformation online. In response to the questions guiding this study, the main findings suggest: (1) statistical data is seen to have several different functions in online public debates; (2) statistical data presentation, no matter how effective, does not have the power to extinguish opposing sentiments that are the product of ideological beliefs; (3) the use of statistics can be a powerful argumentative tool, but not necessarily when presented in isolation or without context; and (4) there is a growing responsibility for science researchers to be more explicit about the implications of their findings due to the accessibility of information in the public sphere online. 


\section{Chapter 7: Future Directions and Conclusion}

This study has illuminated several worthy areas of investigation, and has also indicated the value of discourse analyses more broadly. The scope of this study has been considerably broad, though there are still many areas left untouched by the current investigation. Having pointed to some of the distinct issues within each of the discourses, it appears that there is significant opportunity to explore how more constructive conversations can be held online, particularly as it relates to health sciences and ideologies that oppose the data from that field. What is now a seemingly hostile dialogue has the potential to be a place for education and resource sharing that could be life saving, but more extensive research on that discourse is required. In relation to the findings, it is apparent that the necessity for effective communication strategies on behalf of those in the science community is a dire issue, and that perhaps research focused on facilitating that type of education for scientists with recognition of what is occurring in the public sphere online would be productive. The notion that the onus lies solely on the science community when it comes to the effective communication of their research findings is an invalid one. This point of the current study's findings provides insight for the opportunities available to researchers in discourse studies who seek to explore how science communities can be assisted by the perspectives informed by discourse analyses. Specifically, one key implication for future research resulting from the current study is that a possible area of research has been identified: one that focuses on academic writing strategies tailored to the effective transmission of information from the science field to the public sphere, including the emphasis of social and political contexts, accessibility of 
language and numerical data, and the possibility of creating the role of an academic-lay interpreter.

Finally, the approach taken in this study to explore the public discourse surrounding a specialized knowledge can has the potential to be applied to the information coming from other disciplines. Be it economics, psychology, or law, only to name a few, there is a unique opportunity to apply a discourse analysis much like the one in this study in order to understand how the gaps can be bridged between institutional knowledge and public understanding. This study has evidenced the value in exploring the ways in which specialized information can be misrepresented and misinterpreted, largely as the result of contextual factors and the domains in which the information is being accessed, but it should be noted that different disciplines and the knowledge they produce will inevitably have varied contexts that will necessitate tailored approaches to how their specific findings are shared and who their intended audience is. Understanding this feature of discourse assists in the justification of future research that aims to evaluate how to best serve various academic communities, and the public more broadly, through the investigation of discourse strategies informed by context and medium.

Revisiting the consideration for the construction of scientific knowledge that launched this investigation, we have had the opportunity to explore how those discussed instances of 'doing science activities' have developed and evolved from a discoursal perspective, particularly as it relates to the current state of science-lay discourses and the complex contexts in which they exist. Albeit varied, the influence of accessible numerical data in the public sphere maintains some degree of the authority held by science communities; however, the is a significant threat posed by the misrepresentation and 
resulting misinterpretations of scientific research findings facilitated by the increasingly accessible online platforms where the public discourses exist and continue. Despite attempts from various online platforms where pertinent information is accessed by the public to mitigate the spread of misinformation with numerous restrictions and constraints, it is not hard to come by a celebrity encouraging their online following to believe that terminal cancer can be cured with the consumption of organic blueberries. While the predicament does not seem as though it can be prevented at this stage, there is an opportunity for academic researchers to control the messaging of their findings with respect to these ever-evolving social and communicative challenges. When I reflect upon the engineering students mentioned in this study's background, what they present is an apparent eagerness to devote their efforts and intelligence to creating solutions for some of the world's challenges. I would like to think that this is the aim behind all worthwhile academic research, and that the collaborative, interdisciplinary endeavours proposed by this exploration could contribute, at least in a small way, to making this world a safer and more long-lasting place to be, where the findings of academic research can be to the benefit of all and not just the few. 


\section{Appendices}

Appendix A

Health Science Dataset

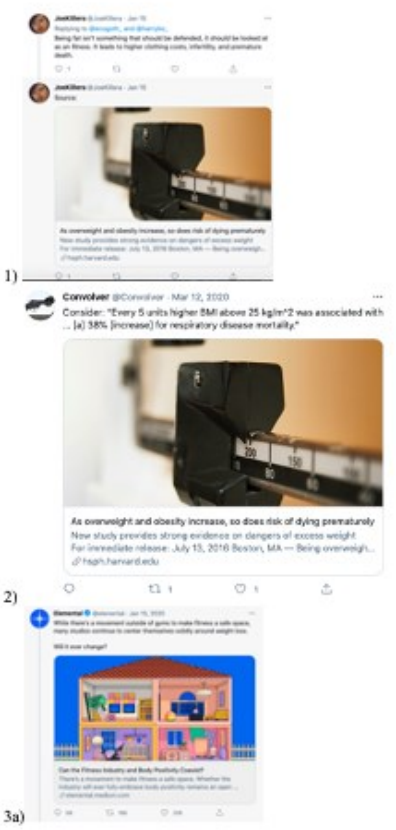




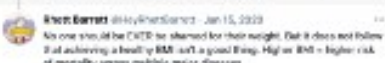

3b)

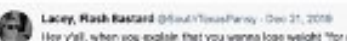

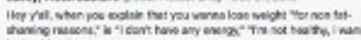

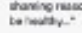

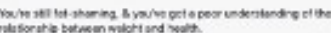

4a)

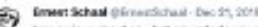

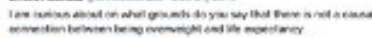

4b)

0 o 0

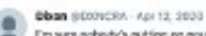

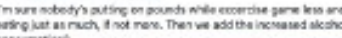

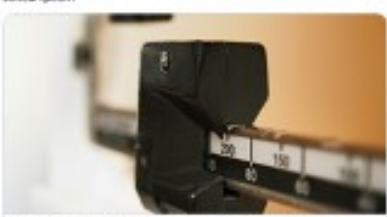

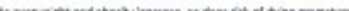

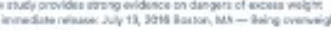

5)

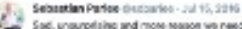

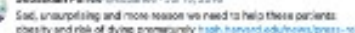

6)

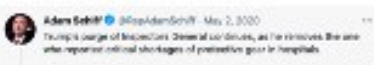

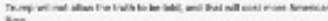

7a)

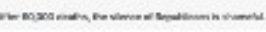




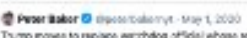

7b)

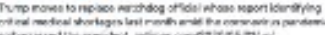

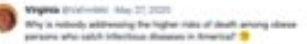

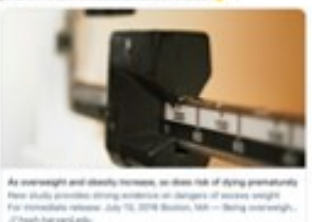

7c)

.... Tatal Aosens Medical ptondicosensmedi . Sep 14, 2016

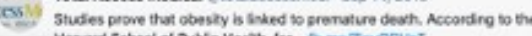

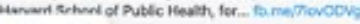

8)

$$
\text { (rollow }
$$

0

s

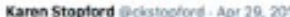

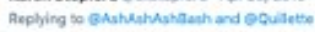

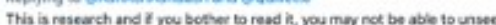
is:

9) $6=$

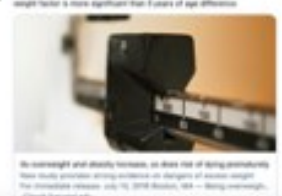

10) 


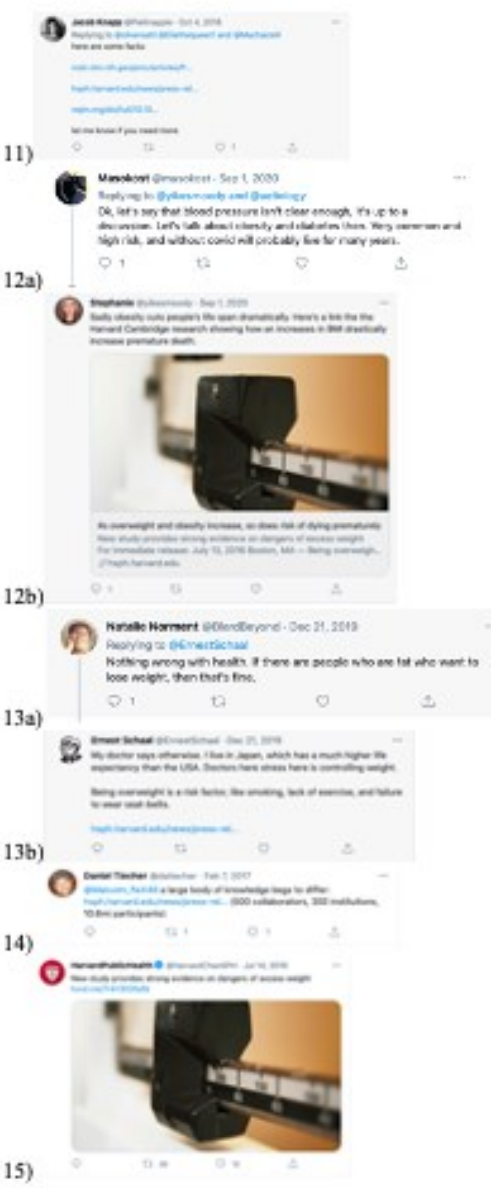




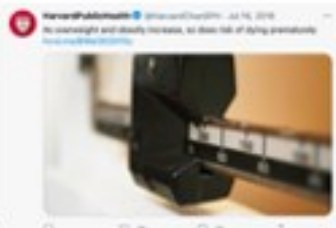

16)

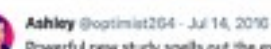

Powerful rew stady soels sut the ouct correlation betweren wight and

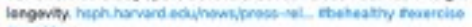
trutrit

17)
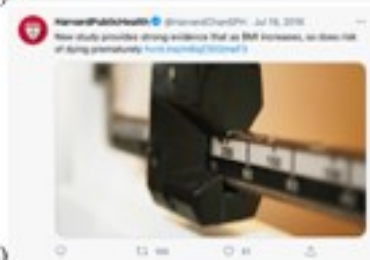

18)

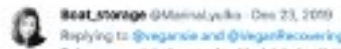

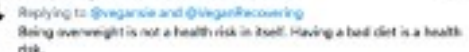

19a)
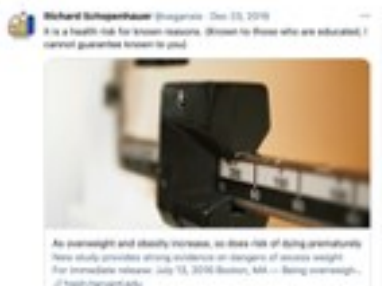

19b) 


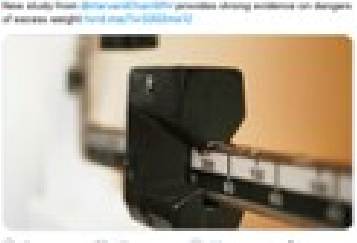

20)

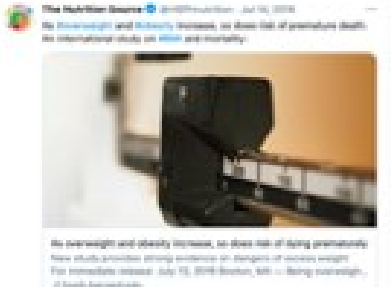

21)

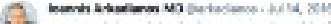

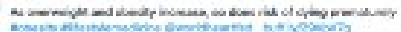

22)

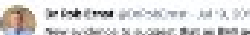

23)

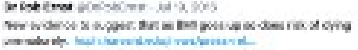

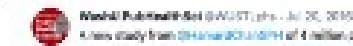

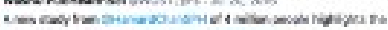

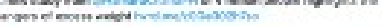

24a)

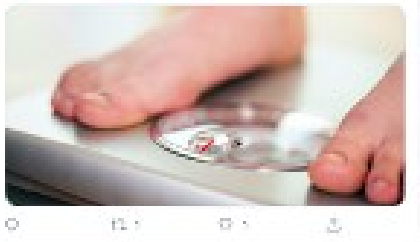

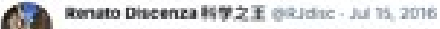

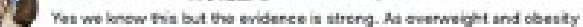

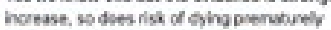

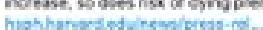

24b)

Q c a $\quad 0$ i


D Howard Lues Mo ohplas - Jul M, 2084

Doesty bils.

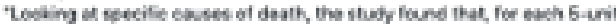

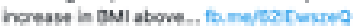

25)

26a)

$$
\text { 2. } 50 \text {. }
$$

$\pm$

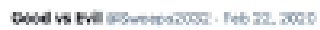

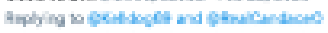

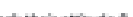

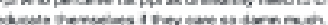

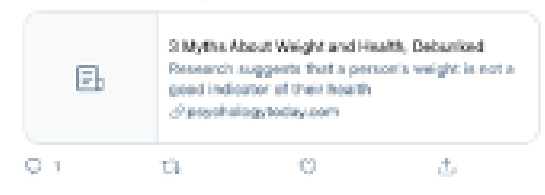

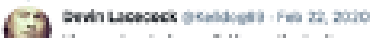

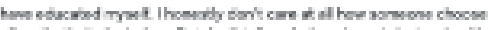

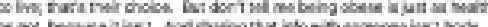

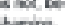

26b)

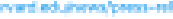

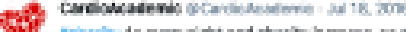

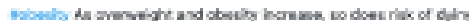

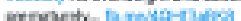

27)

7)
Q 0. $\varnothing$ 3

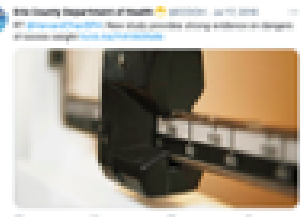

28)

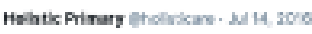

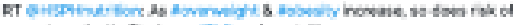

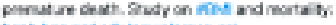

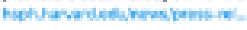

29)

cis

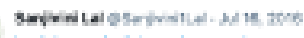

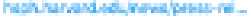

30)

0 t?

$\varnothing$




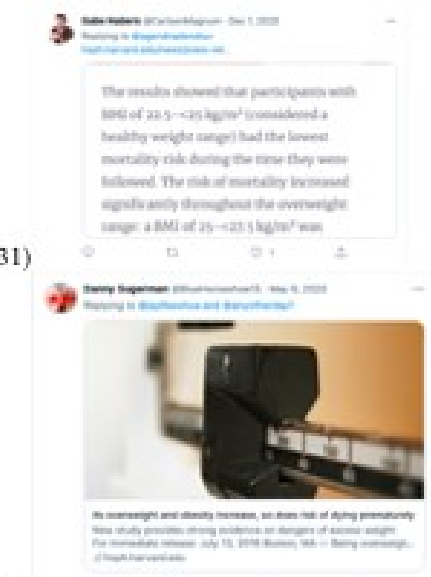

32)

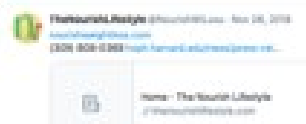

33)

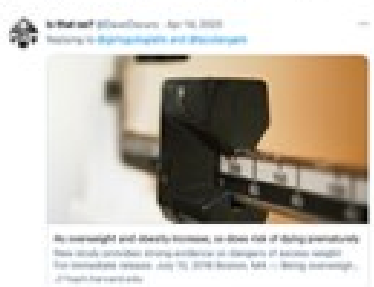

34)

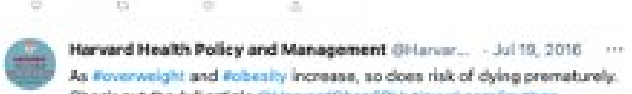

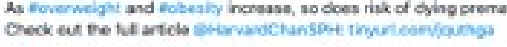

35)

Q a $0+$ s

De. Steven Weiniger oacdrzone - 2429,2016

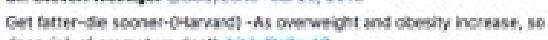

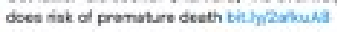

36)
ta 1
0 :
$\pm$ 


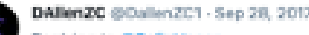

Resting ts escriecioom

So do obese, abnowious Mobeifs. enty seoret.

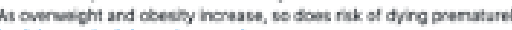
haph herousdoduhemapress red.

37)

○

Oxabefas (stepter) povabefu- 0ec 10, 2017

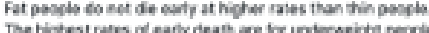

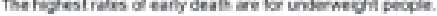

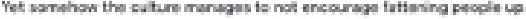

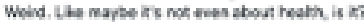

38a)

P.

ta os

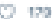

2 Wordalind evertuncaeces - an 26,2095

Plouse stap your bullyit,

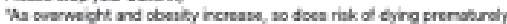

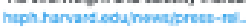

38b)

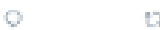

0

0

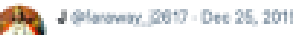

Reoling wo ADenci. Duiour eTwemorstru and 2 cthers haph Lerverdedulhemshoress-el

39)

t.

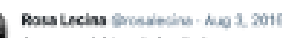

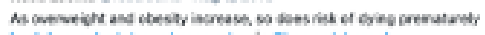

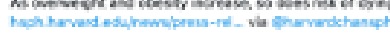

40)

Q

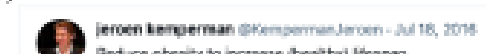

Avdace abeaity to incrasue thesathyi lifeapa)

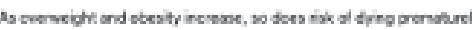

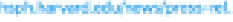

41)

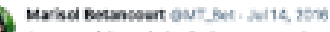

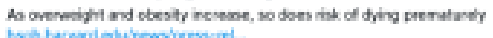

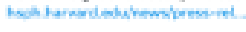

42)
J

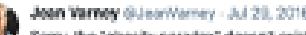

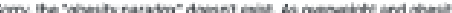

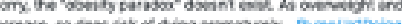

43)

? 


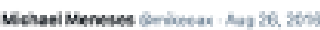

mit

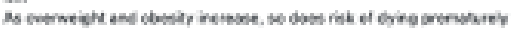

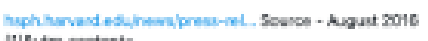

injurycontents

44)

Q

- $\quad *$

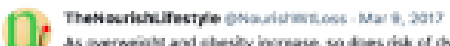

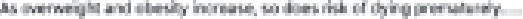

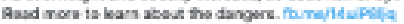

45) Q

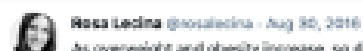

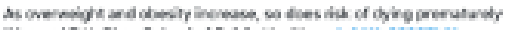

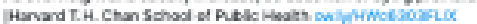

46) P

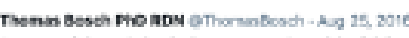

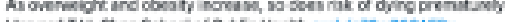

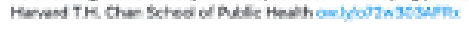

47) O t. O

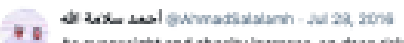

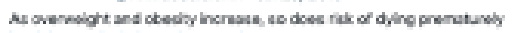

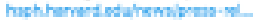

48)
c
ta.
$\varnothing$

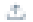

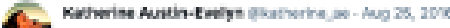

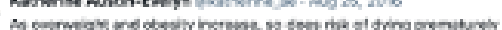

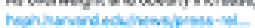

49)

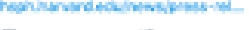

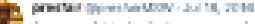

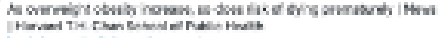

50) a

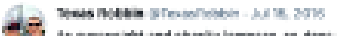

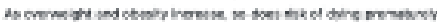

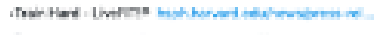

51) 0 व 0 , 0 


\section{A.1 Harvard Public Health Presentation of Findings}

As overweight and obesity increase, so does risk of dying prematurely

New study provides strong evidence on dangers of excess weight

For immediate release: July 13, 2016

Boston, MA - Being overweight or obese is associated with a higher risk of dying prematurely than being normal weight — and the risk increases with additional pounds, according to a large international collaborative study led by researchers at the Harvard T.H. Chan School of Public Health and the University of Cambridge, UK. The findings contradict recent reports that suggest a survival advantage to being overweight - the socalled "obesity paradox."

The study was published online on July 13, 2016 in The Lancet.

The deleterious effects of excess body weight on chronic disease have been well documented. Recent studies suggesting otherwise have resulted in confusion among the public about what is a healthy weight. According to the authors of the new study, those prior studies had serious methodological limitations. One common problem is called reverse causation, in which a low body weight is the result of underlying or preclinical illness rather than the cause. Another problem is confounding by smoking because smokers tend to weigh less than nonsmokers but have much higher mortality rates. "To obtain an unbiased relationship between BMI and mortality, it is essential to analyze individuals who never smoked and had no existing chronic diseases at the start of the study," said Frank Hu, professor of nutrition and epidemiology at Harvard Chan School and a co-leader of the collaboration. Hu stressed that doctors should continue to counsel patients regarding the deleterious effects of excess body weight, which include a higher risk of diabetes, cardiovascular disease, and cancer.

In order to provide more definitive evidence for the association of excess body weight with premature mortality, researchers joined forces in 2013 to establish the Global BMI Mortality Collaboration, which involves over 500 investigators from over 300 global institutions.

"This international collaboration represents the largest and most rigorous effort so far to resolve the controversy regarding BMI and mortality," said Shilpa Bhupathiraju, research scientist in the Department of Nutrition at Harvard Chan School and co-lead author of the study.

For the new study, consortium researchers looked at data from more than 10.6 million participants from 239 large studies, conducted between 1970 and 2015, in 32 countries. A combined 1.6 million deaths were recorded across these studies, in which participants were followed for an average of 14 years. For the primary analyses, to address potential biases caused by smoking and preexisting diseases, the researchers excluded participants who were current or former smokers, those who had chronic diseases at the beginning of the study, and any who died in the first five years of follow-up, so that the group they analyzed included 4 million adults. They looked at participants' body mass index (BMI) - an indicator of body fat calculated by dividing a person's weight in kilograms by their height in meters squared $\left(\mathrm{kg} / \mathrm{m}^{2}\right)$.

The results showed that participants with BMI of $22.5-<25 \mathrm{~kg} / \mathrm{m}^{2}$ (considered a healthy weight range) had the lowest mortality risk during the time they were followed. The risk 
of mortality increased significantly throughout the overweight range: a BMI of $25-<27.5$ $\mathrm{kg} / \mathrm{m}^{2}$ was associated with a $7 \%$ higher risk of mortality; a BMI of $27.5-<30 \mathrm{~kg} / \mathrm{m}^{2}$ was associated with a $20 \%$ higher risk; a BMI of $30.0-<35.0 \mathrm{~kg} / \mathrm{m}^{2}$ was associated with a $45 \%$ higher risk; a BMI of $35.0-<40.0 \mathrm{~kg} / \mathrm{m}^{2}$ was associated with a $94 \%$ higher risk; and a BMI of $40.0-<60.0 \mathrm{~kg} / \mathrm{m}^{2}$ was associated with a nearly three-fold risk. Every 5 units higher BMI above $25 \mathrm{~kg} / \mathrm{m}^{2}$ was associated with about $31 \%$ higher risk of premature death. Participants who were underweight also had a higher mortality risk. Looking at specific causes of death, the study found that, for each 5-unit increase in BMI above $25 \mathrm{~kg} / \mathrm{m}^{2}$, the corresponding increases in risk were $49 \%$ for cardiovascular mortality, $38 \%$ for respiratory disease mortality, and $19 \%$ for cancer mortality. Researchers also found that the hazards of excess body weight were greater in younger than in older people and in men than in women.

Other Harvard Chan School authors included Walter Willett, Fredrick John Stare Professor of epidemiology and nutrition and chair of the Department of Nutrition; and JoAnn Manson, professor of nutrition and epidemiology and chief of the Division of Preventive Medicine at Brigham and Women's Hospital.

Funding for the work of the coordinating center at the Harvard Chan School came from the National Institutes of Health (research grants PO1 CA87969, UM1 CA176726, UM1 CA167552, DK58845, P30 DK046200, and U54CA155626). The coordinating center at the University of Cambridge was funded by the UK Medical Research Council (G0800270), British Heart Foundation (SP/09/002), British Heart Foundation Cambridge Cardiovascular Centre of Excellence, and UK National Institute for Health Research Cambridge Biomedical Research Centre.

"Body-mass index and all-cause mortality: Individual-participant-data meta-analysis of 239 prospective studies in four continents," Emanuele Di Angelantonio, Shilpa N.

Bhupathiraju, David Wormser, Pei Gao, Stephen Kaptoge, Amy Berrington de Gonzalez, Benjamin J. Cairns, Rachel Huxley, Chandra L. Jackson, Grace Joshy, Sarah Lewington, JoAnn E. Manson, Neil Murphy, Alpa V. Patel, Jonathan M. Samet, Mark Woodward, Wei Zheng, Maigen Zhou, Narinder Bansal, Aurelio Barricarte, Brian Carter, James R. Cerhan, Rory Collins, George Davey Smith, Xianghua Fang, Oscar H. Franco, Jane Green, Jim Halsey, Janet S. Hildebrand, Keum Ji Jung, Rosemary J. Korda, Dale F. McLerran, Steven C. Moore, Linda M. O'Keeffe, Ellie Paige, Anna Ramond, Gillian K. Reeves, Betsy Rolland, Carlotta Sacerdote, Naveed Sattar, Eleni Sofianopoulou, June Stevens, Michael Thun, Hirotsugu Ueshima, Ling Yang, Young Duk Yun, Peter Willeit, Emily Banks, Valerie Beral, Zhengming Chen, Susan M. Gapstur, Marc J. Gunter, Patricia Hartge, Sun Ha Jee, Tai-Hing Lam, Richard Peto, John D. Potter, Walter C. Willett, Simon G. Thompson, John Danesh, Frank B. Hu, The Lancet, July 13, 2016, doi: 10.1016/ S0140-6736(16)30175-1 


\section{A.1 Original Presentation of Findings (Lancet)}

Findings All-cause mortality was minimal at $20 \cdot 0-25 \cdot 0 \mathrm{~kg} / \mathrm{m}^{2}$ (HR1 $\cdot 00,95 \%$ CI $0 \cdot 98-1 \cdot 02$ for BMI $20 \cdot 0-<22 \cdot 5 \mathrm{~kg} / \mathrm{m}^{2}$; $1.00,0.99-1.01$ for BMI $\left.22 \cdot 5-<25.0 \mathrm{~kg} / \mathrm{m}^{2}\right)$, and increased significantly both just below this range $(1 \cdot 13,1 \cdot 09-1 \cdot 17$ for BMI $18.5-<20.0 \mathrm{~kg} / \mathrm{m}^{2} ; 1.51,1.43-1.59$ for BMI 15.0-<18.5) and throughout the overweight range $(1.07$, $1.07-1.08$ for BMI $25 \cdot 0-<27.5 \mathrm{~kg} / \mathrm{m}^{2} ; 1 \cdot 20,1 \cdot 18-1.22$ for BMI $\left.27 \cdot 5-<30.0 \mathrm{~kg} / \mathrm{m}^{2}\right)$. The HR for obesity grade 1 (BMI 30.0-<35.0 kg/m²) was 1.45 , 95\% CI 1.41-1.48; the HR for obesity grade $2\left(35.0-<40.0 \mathrm{~kg} / \mathrm{m}^{2}\right)$ was 1.94 , 1.87-2.01; and the HR for obesity grade $3\left(40 \cdot 0-<60 \cdot 0 \mathrm{~kg} / \mathrm{m}^{2}\right)$ was $2 \cdot 76,2 \cdot 60-2 \cdot 92$. For BMI over $25 \cdot 0 \mathrm{~kg} / \mathrm{m}^{2}$, mortality increased approximately log-linearly with BMI; the HR per $5 \mathrm{~kg} / \mathrm{m}^{2}$ units higher BMI was 1.39 (1.34-1.43) in Europe, 1.29 (1.26-1.32) in North America, 1.39 (1.34-1.44) in east Asia, and 1.31 (1.27-1.35) in Australia and New Zealand. This HR per $5 \mathrm{~kg} / \mathrm{m}^{2}$ units higher BMI (for BMI over $25 \mathrm{~kg} / \mathrm{m}^{2}$ ) was greater in younger than older people $(1 \cdot 52$, 95\% CI 1.47-1.56, for BMI measured at 35-49 years vs 1.21, 1.17-1.25, for BMI measured at $70-89$ years; $\left.p_{\text {heterogeneity }}<0 \cdot 0001\right)$, greater in men than women $\left(1 \cdot 51,1 \cdot 46-1 \cdot 56, v s 1 \cdot 30,1 \cdot 26-1 \cdot 33 ; p_{\text {heterogeneity }}<0 \cdot 0001\right)$, but similar in studies with self-reported and measured BMI.

Interpretation The associations of both overweight and obesity with higher all-cause mortality were broadly consistent in four continents. This finding supports strategies to combat the entire spectrum of excess adiposity in many populations. 


\section{Appendix B}

\section{Climate Change Dataset}

Shelby Blecker @BleckerShelby.Dec 3, 2020

Replying to@UN@LA_NCSA and @UNEP

Shelby Blecker @BleckerShelby - Dec 3, 2020

Tesla EV future looks bright. Get ready for more EV cars, trucks and freight by EV. Full statement from Goldman Sachs. Wonder what do they know that @streetsforall doesn't? Clean air vehicles are the

future. @BSSLosAngeles @LA_NCSA twitter.com/SawyerMerritt/..

Q

t]

○

^

5)

(1) Jerald Nott @ccw50 . Dec 2, 2020

Replying to @UN and @UNEP

There is no such thing as global warming or climate change, you fools !!!! The seas are not going to rise !!!!

Q

¿2

○ 3

$\uparrow$

6)

Digital Reason @digital_reason.Dec 2, 2020

Replying to @UN and @UNEP

Quit telling us what to do.

Q

ใช

O

$\uparrow$

Sergey @Sergey66399003 - Dec 2, 2020

Replying to @UN and @UNEP

"...by $6 \%$ per year..." - ?!!!

- Min $26 \%$ per year!

Q

七]

O

ษ 
Steve OH (Majesty... one pronoun is plenty) mOW... - Dec Z, $2020 \quad \ldots$

Replying to eUN and eUNEP

Small Modular Nuclear Reactors.
Q 1
ㄱ.
$\bigcirc 1$

BloodGuard59 puinc94990002 - Dec 2, 2020

cIll: Thorium resctors. They do work and then're safn.
Q 1
0
○

Steve $\mathrm{OH}$ (Majesty... one pronoun is plenty) @Ow... . Dec 3, 2020

I'd like to see Canada take the lead in this tech like we once had with

CANDO reactors. Makes a great deal of sense compared to wind/solar.
Q
(

2)

Sir Brian Crumb (he/she/it) @sirbriancrumb-Dec 2, 2020

Replying to @UN@EcolstArt and @UNEP

Surely decreasing use is the way to tackle production. No need $=$ No income $=$ No production?
Q 1
七า
O

$\uparrow$

Rob Anderson @ULEV_RobA.Dec 2, 2020

Oh - so true, but so counter to the perceived view that consumption is the only measurement of growth. That's what capitalism is built on.

๑

โ2

$\uparrow$

3)

RAJ KUMAR KAPOORIA @KapooriaRaj - Dec 2, 2020

Replying to @UN and @UNEP

There's need to shared travel, policies and promotions to provide homely facilities at or near to working premises. E.g. University's, School's,

Mall's, Bank's, Dispensary's, etc.

Q

t.

0

$\uparrow$ 
8)

Elsasanz @Eldi2 - Dec 2, 2020

Replying to @UN and @UNEP

I don't believe anything and I'm tired of you people. You can't control my mind

Q

†]

ऽ

$\uparrow$

9)

The woed mast decreses fosst tued production by 6\% per

your bo imit estastrochic giobal worming.

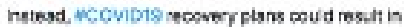

nernesses.

We need uogart aClimatebstien to dose tron

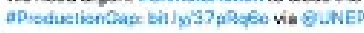

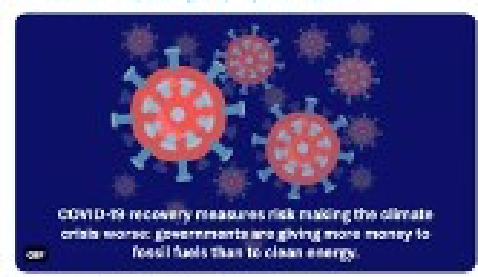

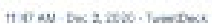

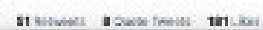

Wattias Krarke emattKranke - Dec 2,2020

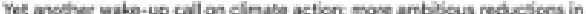

needod, aroues the latast Preduction lap Repor

unep orghevers-and-ston. (t/p)

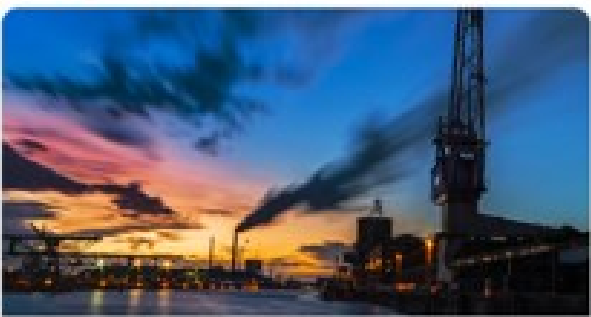

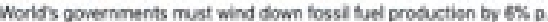

A soecial issue of the Production Gep Peoort - from laading research

aromizations and the UN - finds that the COVD-19 recovery marks . 8 uresorg

10)

Q I

t. 1

$0 \times$

논 


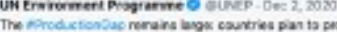

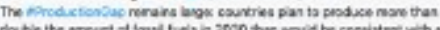

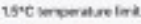

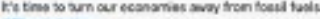

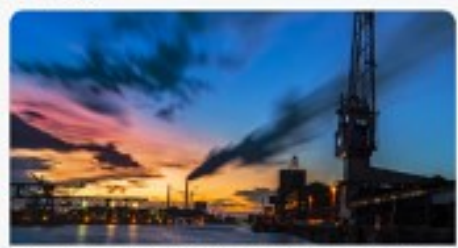

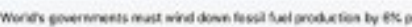

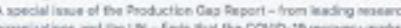
sumpors

11)

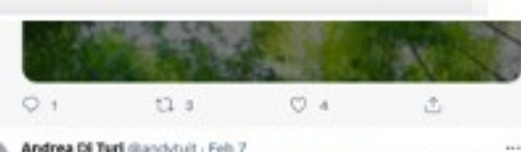

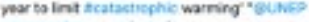

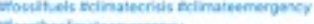

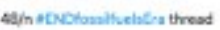

World's governments must wind down fossil fuel production by $6 \%$

12) nor phat to limit 


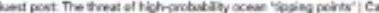

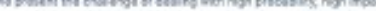

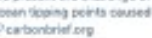

o , th 0

93. In Sxutem gociunen- Feb 24

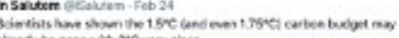

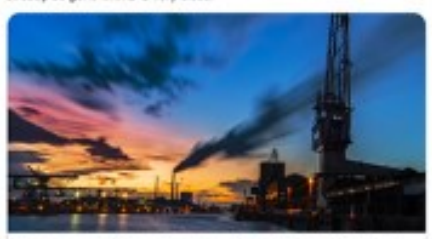

13)

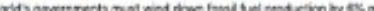

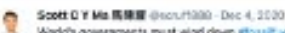

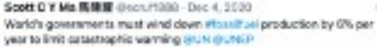

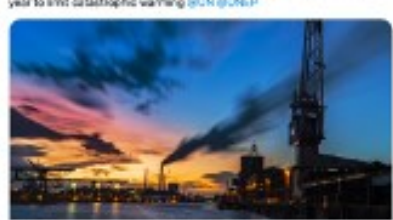

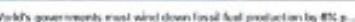

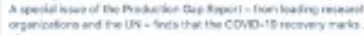

14) 


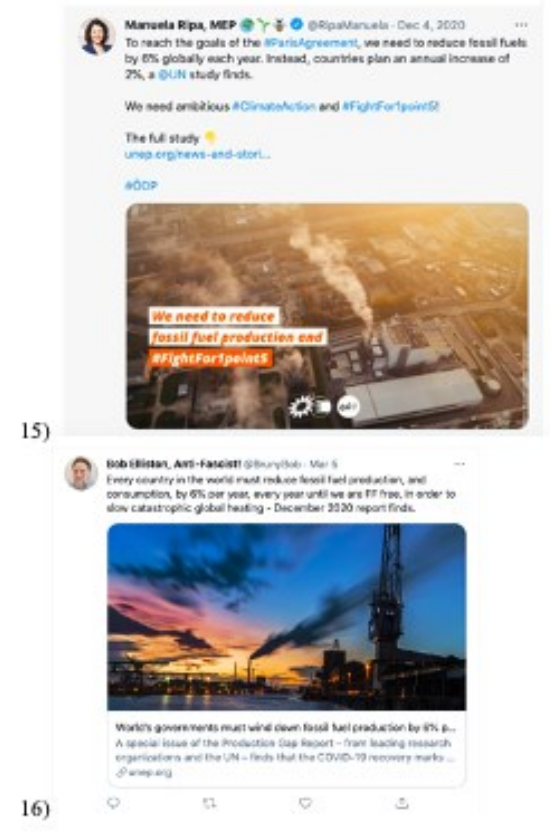




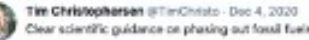

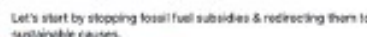

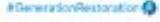

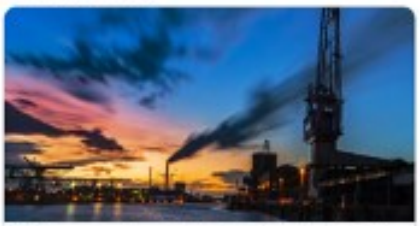

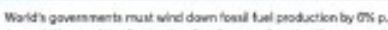

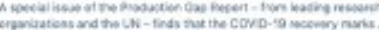
ounese

17)

17. Wey De ascher esentelitionoe Dec 2,2600

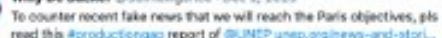

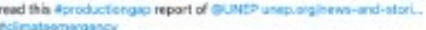

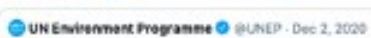

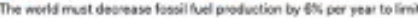
catamopte globs: warming.

mised, eapties are dioming increases

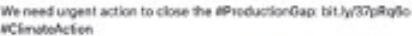

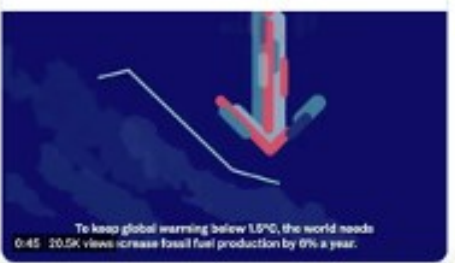

18) 


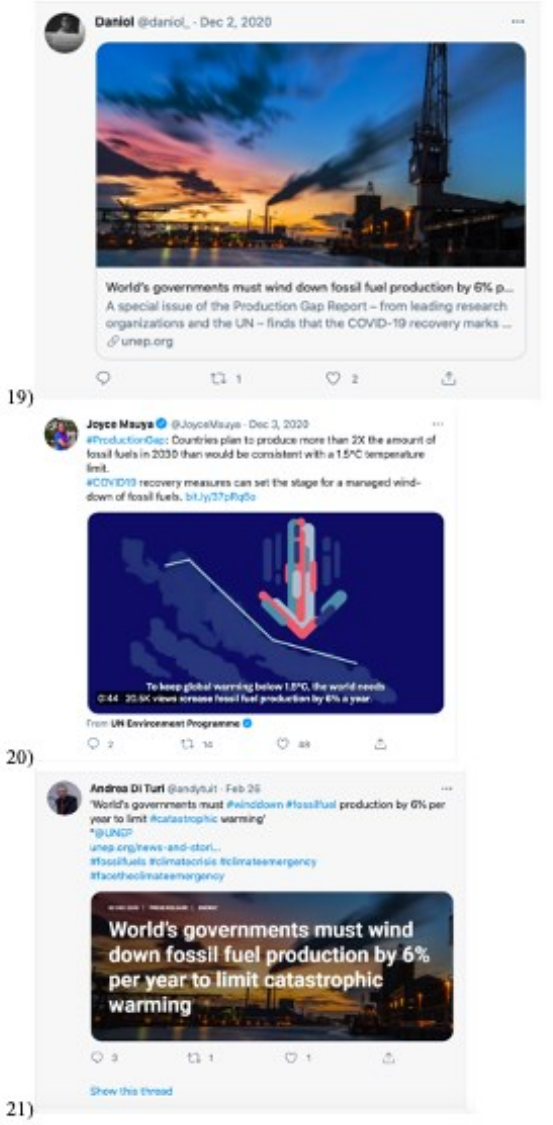




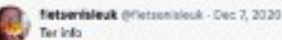

Tor ibs

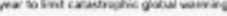

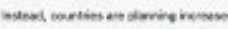

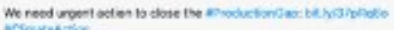

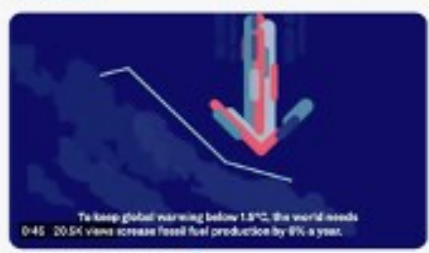

22)

- rucc O orucc Otficial - Dee 2,2020

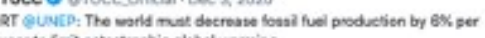

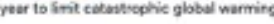

inseed ceurteries are plaming inereoses.

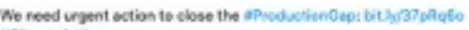

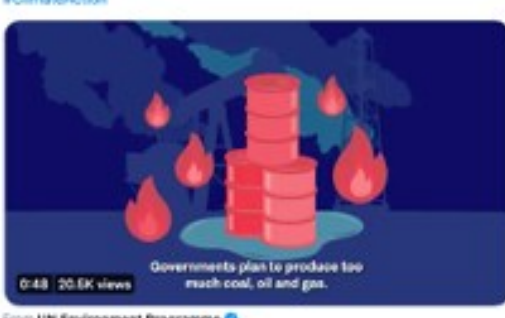

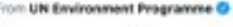

23) 


\section{B.1 United Nations Environmental Programme Presentation of Findings}

\section{Executive Summary}

To limit warming to $1.5^{\circ} \mathrm{C}$ or well below $2^{\circ} \mathrm{C}$, as required by the 2015 Paris Agreement, the world needs to wind down fossil fuel production. Instead, governments continue to plan to produce coal, oil, and gas far in excess of the levels consistent with the Paris Agreement temperature limits.

This report highlights the discrepancy between countries' planned fossil fuel production levels and the global levels necessary to limit warming to $1.5^{\circ} \mathrm{C}$ or $2^{\circ} \mathrm{C}$. This gap is large, with countries aiming to produce $120 \%$ more fossil fuels by 2030 than would be consistent with limiting global warming to $1.5^{\circ} \mathrm{C}$

The COVID-19 pandemic and associated response measures have introduced new uncertainties to the production gap. While global fossil fuel production will decline sharply this year, government stimulus and recovery measures will shape our climate future: they could prompt a return to pre-COVID production trajectories that lock in severe climate disruption, or they could set the stage for a managed wind-down of fossil fuels as part of a "build back better" effort

This special issue of the Production Gap Report looks at how conditions have changed since last year, what this means for the production gap, and how governments can set the stage for a long-term, just, and equitable transition away from fossil fuels. 


\section{B.2 Original Presentation of Findings (Lancet)}

\begin{tabular}{|c|c|c|c|c|}
\hline \multirow{2}{*}{$\begin{array}{l}\text { Period of time } \\
\text { Approaches }\end{array}$} & \multicolumn{2}{|c|}{ 2000-2006 } & \multicolumn{2}{|c|}{2017} \\
\hline & $\mathrm{BU}$ & TD & $\mathrm{BU}$ & TD \\
\hline \multicolumn{5}{|c|}{ Natural sources } \\
\hline Wetlands & $146[102-176]$ & $184[166-196]$ & $145[100-183]$ & $194[155-217]$ \\
\hline Other natural sources & $222[143-306]$ & $36[21-47]$ & $222[143-306]$ & $39[21-50]$ \\
\hline Freshwaters & $159[117-212]$ & & & \\
\hline Geological & $45[18-65]$ & & & \\
\hline Wild animals & $2[1-3]$ & & & \\
\hline Termites & $9[3-15]$ & & & \\
\hline Permafrost soils (direct) & $1[0-1]$ & & & \\
\hline Biogenic ocean (open and coastal) & $6[4-10]$ & & & \\
\hline Total natural sources & $368[245-482]$ & $220[198-243]$ & $367[243-489]$ & 232 [194-267] \\
\hline \multicolumn{5}{|c|}{ Anthropogenic sources } \\
\hline Agriculture and waste & $189[176-203]$ & $203[194-213]$ & $213[198-232]$ & $227[205-246]$ \\
\hline Enteric ferm. and manure & $102[99-108]$ & & $115[110-121]$ & \\
\hline Landfills and waste & $59[54-61]$ & & $68[64-71]$ & \\
\hline Rice cultivation & $28[23-34]$ & & $30[24-40]$ & \\
\hline Fossil fuels & $106[90-123]$ & $92[70-113]$ & $135[121-164]$ & $108[91-121]$ \\
\hline Coal mining & $29[22-39]$ & & $44[31-63]$ & \\
\hline Oil and gas & $72[59-83]$ & & $84[72-97]$ & \\
\hline Industry & $2[0-5]$ & & $3[0-8]$ & \\
\hline Transport & $4[1-10]$ & & $4[1-13]$ & \\
\hline Biomass and biof. burn. & $33[26-49]$ & $30[27-36]$ & $29[24-38]$ & $28[25-32]$ \\
\hline Biomass burning & $20[15-35]$ & & $16[11-24]$ & \\
\hline Biofuel burning & $12[9-14]$ & & $13[10-14]$ & \\
\hline Total anthropogenic sources & $328[315-352]$ & $324[308-341]$ & 380 [359-407] & $364[340-381]$ \\
\hline Total sources & $696[560-834]$ & $546[538-555]$ & $747[602-896]$ & $596[572-614]$ \\
\hline \multicolumn{5}{|c|}{ Sinks } \\
\hline Total chemical loss & & $510[501-515]$ & & $531[502-540]$ \\
\hline Soil uptake & $30[11-49]$ & $35[30-41]$ & 30 [11-49] & $40[37-47]$ \\
\hline Total sinks & & $546[531-555]$ & & $571[540-585]$ \\
\hline
\end{tabular}




\section{Appendix C}

Vaccine Dataset

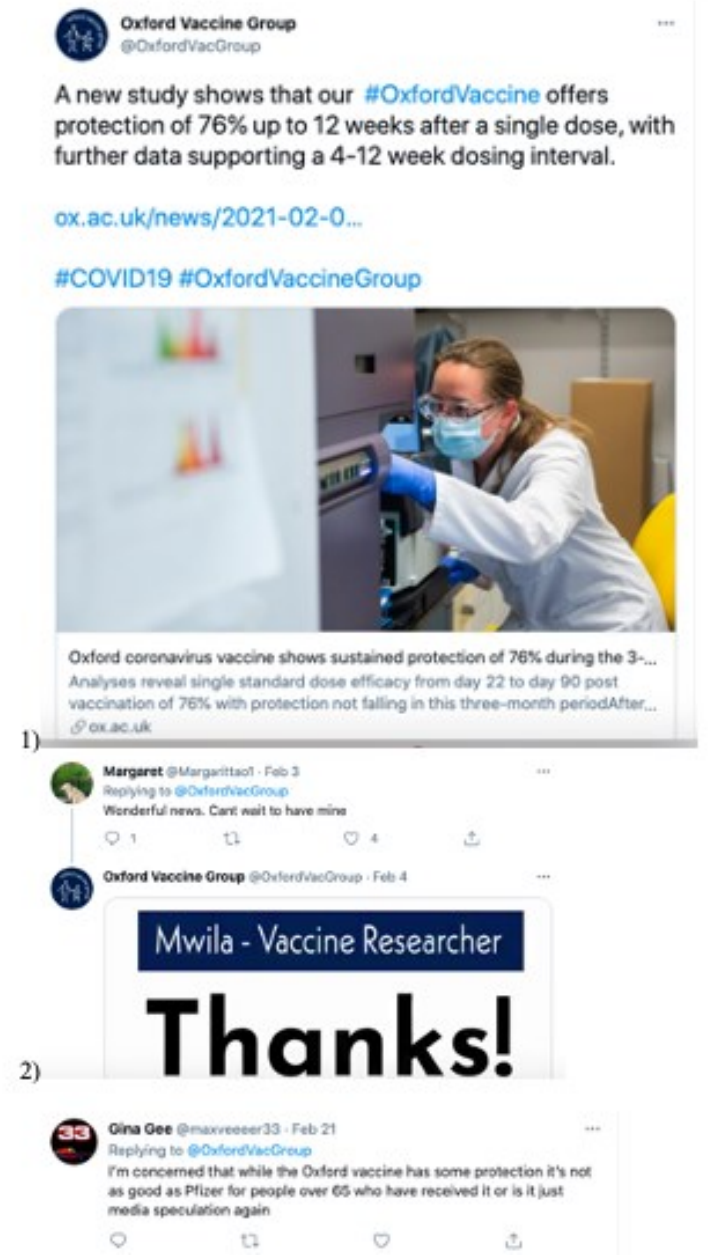


f.5. De. Yan Yu eyanyu247 , Feb 11

Aeplying to GorfoedVacGroup

joxforovecleoup vaccine is made, and how $h$ works. Ooal is to be

let us know how we can imgrove the content!

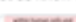

4a)

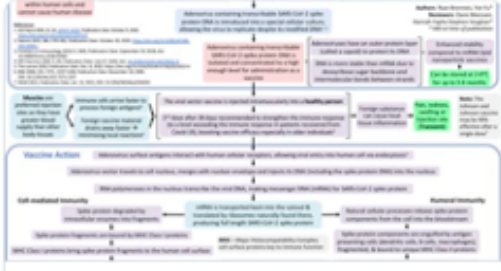

Adenovins Vector Vaccines Against COVO-19. Production and

Oedianguide vealoarye

$0.12+2$

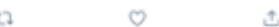

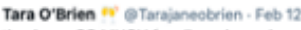

thank you SO MUCH for all you have done. Fm so very grateful $h$. My $74 y r$ Mom has had the Oxford vaccine, but lives in South Africa foo half of the year.

Should she rather not go back there?

4b)$$
\text { 인 }
$$

0

12. Sangita Bharat Panchal @bharat_sangita - Feb a

Replying to $@$ OxfordVac:Group.

sulublas

5)

$\diamond$

โา

O 2

$\uparrow$

(A) Cathy $\bullet$ eSaltyDuchess - Feb

Replying to @OxfordVacGroup

What a fantastic job all those involwed in developing, trialing and rolling out the vaccine have done

Q

t.

O 4

$\widehat{\varphi}$ 
Mike @msmcglau . Feb 3

Replying to @OxfordVacGroup

Congrats Oxford (from a Pfizer fan)

7)
$\diamond$
¿2.
0
$\uparrow$

Susan Cowling @Susan2708 - Feb 4

Replying to @OxfordVacGroup

Awesome results thank you

$\varnothing$

t]

$\circlearrowleft$

$\uparrow$

8)

9. Davina @davinabeauty + Feb 8

Replying to @OxfordVacGroup

It is a similar protection \% to the south South African variant?

๑

七า

○

ثิ

9)

7. Tara O'Brien W' @arajaneobrien - Feb 12

6.1. Replying to @OxfordVacGroup

thank you SO MUCH for all you have done. I'm so very grateful $\mathrm{d}$

My 74 yr Mom has had the Oxford vaccine, but lives in South Africa for

half of the year.

Should she rather not go back there?

Q

t]

个

10)

Q. AndY B @Bomen85A - Feb 3

What a lead of shit. How can you even call it a vaccine ? I dare you to post

the survival rates for age groups. Not averyons naeds this 30 callad

vactire.

Q

12

11a)

Sab ürosickitata - Feb 3

Seb Erosickiteta - Feb-3

Idk if you krow, $A$ ady, but the Oxford 've Group aren't the NuIS or ONS,

so l'd direct your survival rate queries there my friend. @NHSuk @ONS

(I've even helped you cut!)

Q 1

$\uparrow$

11b) Show replies 
7. Anor B OBomenasal- Fab 3

Yeas thanks for the help. Stll not a vacoine through is in?

O 12

ta.

1. Icl, Five no idea what yourte talking about 8

0,12

ti.

Andr B QBowenass - Feb 3

$\circ$

2.

Seb wrosicutieta F Feb 3

I'm intrigued to fied out uhty you think it's not a "vaccine", seems lieve a

it to

Anor B ebowenasd - Feb 3

What's the fundememals of a vaccine $n$ Sico trimimission stop you

getting virus. If a were an end consamer product it wovidn? be allowed

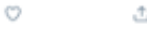

And B B PBownasad. Feb ]

Not to mention the lack of testing done on $\mathrm{k}$. Mrs laughable.

11c)

$0 \quad 0 \quad 01$

(2) Merapiman Emerapimant - Feb 20

Aleplying to eoxfordVaccoroup

You must now be realsing how stupidly nave you were beth with you original data presentation and secondly with your demand that the vaccine be sold at cost.

All you have achioves is so devalue it and cause a good vaccine to be A A jectod.

12)

(7) Melissa Enders Gmelyanenders - Feb 23

Replying to eOxlordvacoroup

Saw this yet? Genomic sequencing.

C) The Washington Post 0 ewaukingtonpest - Feb 23 Coronavirus medical mystery, Baby with high viral load puzzles researchers mapost/3bmacti

13)

t)

O

$\pm$ 
Ellen Kushner the Writer 0 pecllenkistiner - Feb 11

Creat news! I's in the US trial for this, so watching eajerty

- Oxford Vaccine Greup eoxfordVacCroup - Feb 3

A new study shows that our moxtordvaccine ofters protection of $76 \%$

up to 12 woeks after a single done, with further data supporting a 4.

12 woek dosing interval.

ar acukinems/2021-02-0.

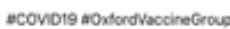

14)

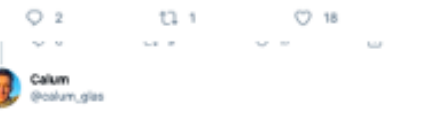

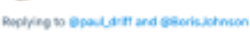

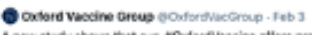

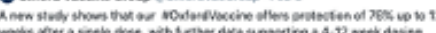

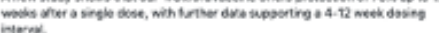

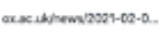

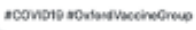

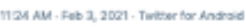

$\begin{array}{llll}0 & \mathrm{t} & 0 & 3\end{array}$

15a)

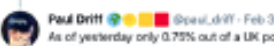

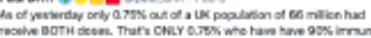

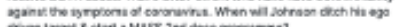

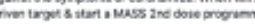

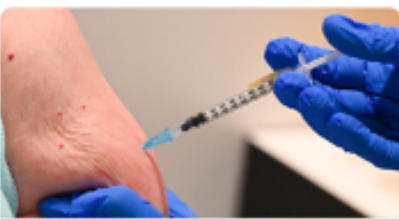

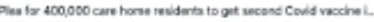

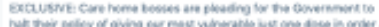

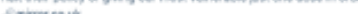

0.

15b) crum 


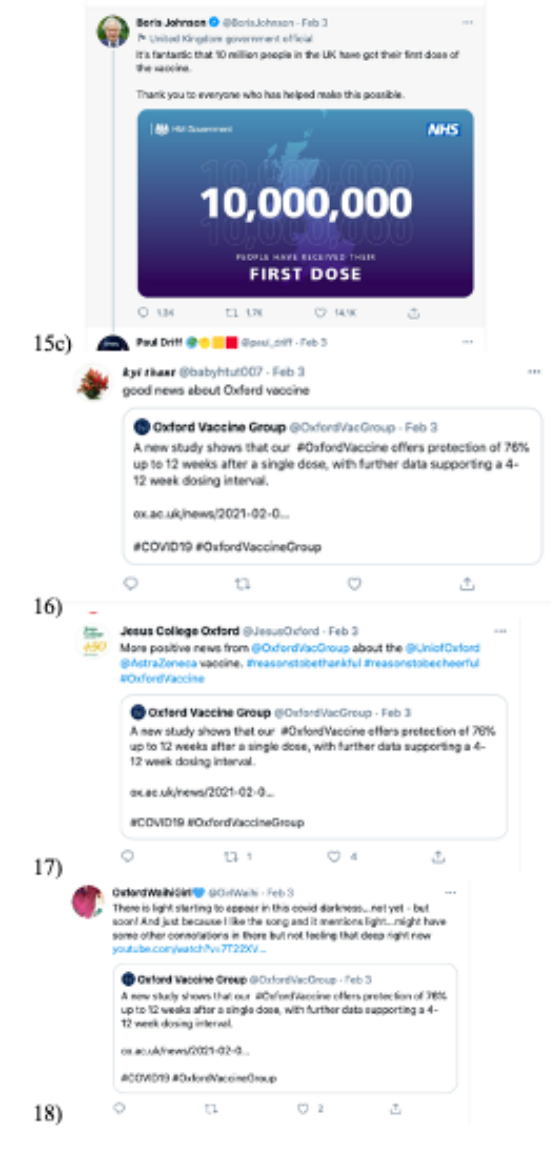

6. wivek aberve enveibures 3 Fob 3

Emegtimal

T) Oxtors Vacoine Grow soctorstrachoup - Feb 3

A new study shows that our mCafordVaceine affers protection of $76 x$

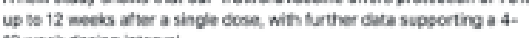

12 mesk dosing imerval

ar.acukhewa/2021-60-0.

aconots arodondwcineorsup

19)

व 0 s




\section{C.1 Oxford Vaccine Group Presentation of Findings}

'Researchers at the University of Oxford have today published in Preprints with The Lancet an analysis of further data from the ongoing trials of the vaccine. In this, they reveal that the vaccine efficacy is higher at longer prime-boost intervals, and that a single dose of the vaccine is $76 \%$ effective from 22- to up to 90-days post vaccination.

In this preprint, which is currently under review at The Lancet, they report on an analysis of additional data to include information from the trial up to the $7_{\text {th }}$ December 2020, which includes a further 201 cases of primary symptomatic COVID-19 (332 cases from 131 reported in previously), They report that the effect of dosing interval on efficacy is pronounced, with vaccine efficacy rising from $54.9 \%$ with an interval of less than six weeks to $82.4 \%$ when spaced 12 or more weeks apart.

They also detail that a single standard dose of the vaccine is $76 \%$ effective at protecting from primary symptomatic COVID-19 for the first 90 days post vaccination, once the immune system has built this protection 22 days after the vaccination, with the protection showing little evidence of waning in this period.

Professor Andrew Pollard, Chief Investigator of the Oxford Vaccine Trial, and co-author, said:

'These new data provide an important verification of the interim data that was used by more than 25 regulators including the MHRA and EMA to grant the vaccine emergency use authorisation.

'It also supports the policy recommendation made by the Joint Committee on Vaccination and Immunisation (JCVI) for a 12-week prime-boost interval, as they look for the optimal approach to roll out, and reassures us that people are protected from 22 days after a single dose of the vaccine.' 
The exploratory analyses presented in this preprint suggest that it is the dosing interval and not the dosing level which has a great impact on the efficacy of the vaccine. This is in line with previous research supporting greater efficacy with longer prime-boost intervals done with other vaccines such as influenza, Ebola and malaria.

The authors also report further on the potential for the vaccine to reduce transmission of the virus, based on swabs obtained from volunteers in the UK arms of the trial with a $67 \%$ reduction after the first dose of the vaccine.

They also hope to report data regarding the new variants in the coming days, and expect the findings to be broadly similar to those already reported by fellow vaccine developers.'

\section{C.2 Original Presentation of Findings (Lancet)}


Findings Between April 23 and Dec 6, 2020, 24422 participants were recruited and vaccinated across the four studies, of whom 17178 were included in the primary analysis (8597 receiving ChAdOx1 nCoV-19 and 8581 receiving control vaccine). The data cutoff for these analyses was Dec 7, 2020. 332 NAAT-positive infections met the primary endpoint of symptomatic infection more than 14 days after the second dose. Overall vaccine efficacy more than 14 days after the second dose was $66 \cdot 7 \%$ (95\% CI 57.4-74.0), with 84 (1.0\%) cases in the 8597 participants in the ChAdOx1 nCoV-19 group and $248(2.9 \%)$ in the 8581 participants in the control group. There were no hospital admissions for COVID-19 in the ChAdOx1 nCoV-19 group after the initial 21-day exclusion period, and 15 in the control group. $108(0.9 \%)$ of 12282 participants in the ChAdOx1 nCoV-19 group and 127 (1.1\%) of 11962 participants in the control group had serious adverse events. There were seven deaths considered unrelated to vaccination (two in the ChAdOx1 nCov-19 group and five in the control group), including one COVID-19-related death in one participant in the control group. Exploratory analyses showed that vaccine efficacy after a single standard dose of vaccine from day 22 to day 90 after

vaccination was $76 \cdot 0 \%(59 \cdot 3-85 \cdot 9)$. Our modelling analysis indicated that protection did not wane during this initial 3-month period. Similarly, antibody levels were maintained during this period with minimal waning by day 90 (geometric mean ratio [GMR] 0.66 [95\% CI 0.59-0.74]). In the participants who received two standard doses, after the second dose, efficacy was higher in those with a longer prime-boost interval (vaccine efficacy $81 \cdot 3 \%$ [95\% CI 60 · 3-91·2] at $\geq 12$ weeks) than in those with a short interval (vaccine efficacy $55 \cdot 1 \%[33 \cdot 0-69 \cdot 9]$ at $<6$ weeks). These observations are supported by immunogenicity data that showed binding antibody responses more than two-fold higher after an interval of 12 or more weeks compared with an interval of less than 6 weeks in those who were aged 18-55 years (GMR 2.32 [2:01-2:68]).

Lancet 2021; 397: 881-91

Published Online

February 19, 2021

https://doi.org/10.1016/

S0140-6736(21)00432-3

\section{This online publication has been \\ corrected. The corrected version \\ first appeared at thelancet.com \\ on March 4, 2021}

\section{Appendix D}

Twitter Study (2020) 


\section{Large portion of Twitter users regularly get news on the site}

$\%$ of each social media site's users who regularly get news there

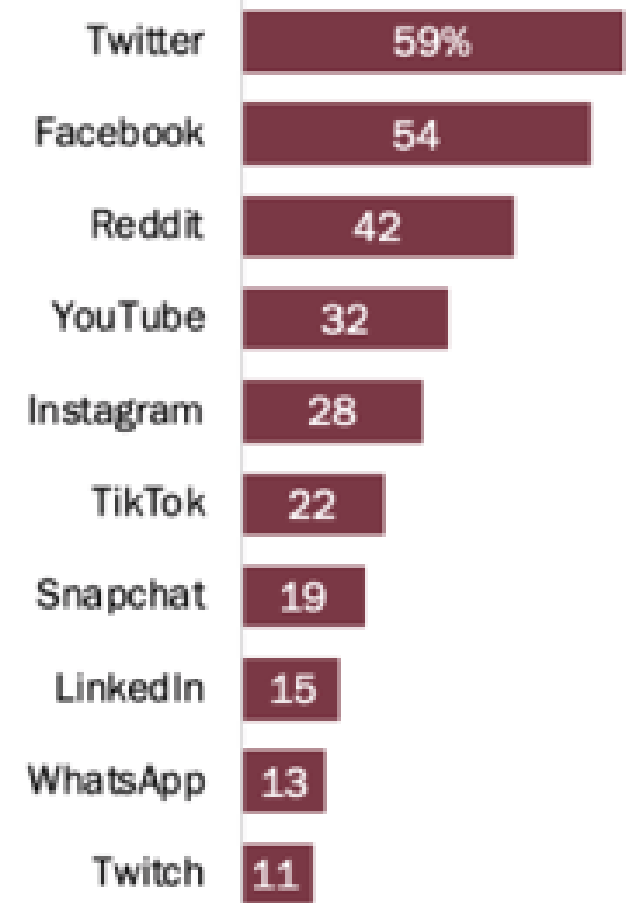

Note: Tumbir not shown due to insufficient sample size.

Source: Survey of U.S. adults conducted Aug. 31-Sept. 7, 2020.

"News Use Across Social Media Platforms in $2020^{\prime \prime}$

\section{PEW RESEARCH CENTER}




\section{References}

Adelswärd, V., \& Sachs, L. (1998). Risk discourse: Recontextualization of numerical values in clinical practice. Text \& Talk, 18(2), 191-210.

Bernstein, B. (2000). Pedagogy, symbolic control, and identity. Rowman \& Littlefield Publishers.

Blackledge, A. (2002). The discursive construction of national identity in multilingual Britain. Journal of Language, Identity, and Education, 1(1), 67-87.

Burke, K. (1969). A rhetoric of motives. University of California Press.

Carvalho, A. (2000). Discourse analysis and media texts: a critical reading of analytical tools. Paper presented at the CECS - Comunicações.

http://hdl.handle.net/1822/3137

Carvalho, A. (2008). Media (ted) discourse and society: Rethinking the framework of critical discourse analysis. Journalism Studies, 9(2), 161-177.

Chouliaraki, L. (2000). Political discourse in the news: democratizing responsibility or aestheticizing politics?. Discourse \& Society, 11(3), 293-314.

Deleuze, G. (1988) Foucault (Minneapolis, MN, University of Minnesota Press).

Di Angelantonio, E., Bhupathiraju, S. N., Wormser, D., Gao, P., Kaptoge, S., De

Gonzalez, A. B., ... \& Hu, F. B. (2016). Body-mass index and all-cause mortality: individual-participant-data meta-analysis of 239 prospective studies in four continents. The Lancet, 388(10046), 776-786.

Gee, J. P. (2004). An introduction to discourse analysis: Theory and method. Routledge.

Gee, J. P. (2016). Discourse analysis matters: Bridging frameworks. Journal of Multicultural Discourses, 11(4), 343-359. 
Foucault, M. (1972) The archaeology of knowledge, A.M. Sheridan Smith, trans. New York, Pantheon Books.

Graham, L. J. (2011). The product of text and 'other' statements: Discourse analysis and the critical use of Foucault. Educational Philosophy and Theory, 43(6), 663-674.

Hajer, M. A. (1995). The politics of environmental discourse: Ecological modernization and the policy process. Oxford: Oxford University Press.

Hajer, M. (2005) Coalitions, practices, and meaning in environmental politics: From acid rain to BSE. In D. Howarth \& J. Torfing (eds.), Discourse theory and European politics (pp. 299-315). Basingstoke and New York: Palgrave Macmillan.

Holliday, A. (2015). Researching Writing. In B. Paltridge \& A. Phakiti (Eds.), Research methods in applied linguistics: A practical resource (pp. 257-267). Bloomsbury Academic.

Jackson, R. B., Saunois, M., Bousquet, P., Canadell, J. G., Poulter, B., Stavert, A. R., ... \& Tsuruta, A. (2020). Increasing anthropogenic methane emissions arise equally from agricultural and fossil fuel sources. Environmental Research Letters, 15(7), 071002.

Kuhn, T. S. (2012). The structure of scientific revolutions. University of Chicago press.

Linell, P. (1998). Discourse across boundaries: On recontextualizations and the blending of voices in professional discourse. Text \& Talk, 18(2), 143-158.

Marsh, J. (2007). New literacies and old pedagogies: Recontextualizing rules and practices. International Journal of Inclusive Education, 11(3), 267-281.

Mulkay, M. (1979). Knowledge and utility: Implications for the sociology of knowledge. Social Studies of Science, 9(1), 63-80. 
Nystrand, M., \& Duffy, J. (2003). Towards a rhetoric of everyday life: New directions in research on writing, text, and discourse. University of Wisconsin Press.

Pennycook, A. (1994). Incommensurable discourses?. Applied linguistics, 15 (2), 115 138.

Potter, J. (1996). Representing reality: Discourse, rhetoric and social construction. Sage.

Sam, C. H. (2019). Shaping discourse through social media: Using Foucauldian discourse analysis to explore the narratives that influence educational policy. American Behavioral Scientist, 63(3), 333-350.

Smart, G. (2011). 15. Argumentation across Web-based organizational discourses: The case of climate change. In Handbook of communication in organisations and professions (pp. 363-386). De Gruyter Mouton.

Smart, G. (2013). The discursive production and impairment of public trust through rhetorical representations of science: The case of global climate change. In Discourses of trust (pp. 252-266). Palgrave Macmillan.

Smart, G. (2016). Discourse coalitions, science blogs, and the public debate over global climate change. In M. Reiff \& A. Bawarshi (Eds.), Genre and the performance of publics (157-177). Logan: Utah State University Press.

doi:10.7330/9781607324430.c008.

Stillar, G. F. (1998). Analyzing everyday texts: Discourse, rhetoric, and social perspectives. SAGE Publications, Inc., https://www.doi.org/10.4135/9781452233383 